NOTE: This is an Author's Accepted Manuscript of an article published in CENTRAL

EUROPEAN JOURNAL OF ENGINEERING [VOL 1, ISSUE 4, (2011)] [copyright Versita sp.

$z$ o.o.]. The original publication is available at www.springerlink.com:

http://dx.doi.org/10.2478/s13531-011-0038-1.

To cite this article: Santos, R.M., Kawaji, M. (2011). Gas-Liquid Slug Formation at a

Rectangular Microchannel T-Junction: A CFD Benchmark Case. Central European Journal of

Engineering, 1(4), 341-360.

\title{
Gas-Liquid Slug Formation at a Rectangular Microchannel T-Junction: A CFD Benchmark Case
}

\author{
Rafael M. Santos ${ }^{1}$, Masahiro Kawaji ${ }^{2}$ \\ ${ }^{1}$ Department of Chemical Engineering \\ Katholieke Universiteit Leuven \\ Leuven, Belgium \\ rafael.santos@alumni.utoronto.ca \\ ${ }^{2}$ Department of Chemical Engineering and Applied Chemistry \\ University of Toronto \\ Toronto, Ontario, Canada \\ masahiro.kawaji@utoronto.ca
}

\begin{abstract}
Computational fluid dynamics (CFD) is an important tool for development of microfluidic systems based on gas-liquid two-phase flow. The formation of Taylor slugs at microchannel T-junctions has been studied both experimentally and numerically, however discrepancies still exist because of difficulties in correctly representing experimental conditions and uncertainties in the physics controlling slug flow, such as contact line and velocity slip. In this paper detailed methods and results are described for the study of Santos and Kawaji [1] on the comparison of experimental results and numerical modeling. The system studied consisted of a rectangular microchannel T-junction nominally $100 \mu \mathrm{m}$ in hydraulic diameter, used to generate Taylor slugs from air-water perpendicular flow. The effect of flow rates on parameters such as slug length, velocity slip, void fraction and two-phase frictional pressure drop were studied. Numerical simulation was performed using FLUENT volume-of-fluid (VOF) model. It is proposed in this paper that this microfluidic problem be taken up by researchers in the field as a benchmark case to test other numeric codes in comparison to FLUENT on the prediction of micro-scale multiphase flow, and also to model in more detail the experimental system described to obtain greater accuracy in prediction of microfluidic slug formation.
\end{abstract}

Keywords: Benchmark, Computational fluid dynamics, Microchannel, Multiphase flow, T-Junction, Taylor slug, Volume-of-fluid

\section{Nomenclature}

Letters and Abbreviations:

A: Cross-sectional area $\left(\mathrm{m}^{2}\right)$

C: Chisholm coefficient

D: Channel diameter $(\mathrm{m})$ 
Dist: Tubing length occupied by water during start-up $(\mathrm{cm})$

f: Frequency $(\mathrm{Hz})$

g w: gas and water inlet flow rates $(\mathrm{ml} / \mathrm{h})$

g: Gravitational acceleration $\left(\mathrm{m} / \mathrm{s}^{2}\right)$

H: Measurement length (m)

L: Length (m)

Le: Entrance length (m)

P: Static pressure $(\mathrm{Pa})$

$\mathrm{Q}$ : Flow rate $\left(\mathrm{m}^{3} / \mathrm{s}\right)$

$\mathrm{R}$ : Measurement radius (m)

Re: Reynolds number

S: Velocity slip

t: Time (s)

U: Superficial velocity $(\mathrm{m} / \mathrm{s})$

$\mathrm{v}$ : Velocity $(\mathrm{m} / \mathrm{s})$

$\mathrm{V}$ : Volume $\left(\mathrm{m}^{3}\right)$

$\mathrm{x}, \mathrm{y}, \mathrm{z}$ : Cartesian coordinates (m)

$\mathrm{X}$ : Lockhart-Martinelli parameter

$\mathrm{Z}$ : Coordinate direction (m)

Greek letters:

$\beta$ : Homogeneous void fraction

$\Delta$ : Difference/change

$\varepsilon$ : Void fraction

$\theta$ : Contact angle (degrees)

$\mu$ : Dynamic viscosity $(\mathrm{kg} / \mathrm{m} \cdot \mathrm{s})$

$\rho$ : Density $\left(\mathrm{kg} / \mathrm{m}^{3}\right)$

$\varphi_{\mathrm{L}}{ }^{2}$ : Two-phase frictional multiplier

$\omega$ : Time step (s)

$\Omega$ : Volume fraction

Subscripts:

branch: Gas inlet channel flow

$\mathrm{C}$ : Continuous phase

ch: Channel

cell: Computational cell

exp: Experimental result

free: Tubing plus syringe occupied by air

g: Gas flow

G: Gas phase

h: Hydraulic

I,II: Upward/Downward initial flow sequence

i: Time stepping counter

in: Water inlet channel flow

L: Liquid phase

max: Maximum

out: Outlet channel flow

S: Air slug phase

SP: Single phase

ST: Static

TP: Two phase

tube: Teflon tubing

w: Water flow

YT: Syringe plus tubing

\section{Introduction}

A limited number of researchers have performed studies to identify gas-liquid slug flow behaviour in micrometer-scale T-junction channels [1,2], with most recent work focussing on liquid-liquid flow [3,4]. The present authors have published a detailed experimental and numerical study on gas-liquid Taylor slug flow in a microfluidic T-junction with nearly square microchannels of $100 \mu \mathrm{m}$ nominal hydraulic diameter [1]. This 
former study was novel in being the first to compare experimental and numerical results on microfluidic gasliquid flow. Several unique approaches were introduced to tackle the difficulties of this field. Herein, this former study is explored in even deeper detail, including thorough explanations on the numerical and experimental procedures, and complete sets of data. It is the intention of the present authors that this work be used as a computational fluid dynamics (CFD) benchmark case for investigation of Taylor flow in microchannels.

The principal reason for the increasing attention on microfluidic devices are the numerous emerging applications of microfluidics that promise to provide technological innovations not realizable with conventional channels. In particular, gas-liquid two-phase flows in microchannels often exhibit different flow behaviour than macro-sized conduits and the trajectory of fluidic particles in microchannels can be controlled precisely. At the micro-scale there is increased importance and effect of surface tension forces, while gravitational forces become negligible, and inertial, shearing and drag forces have a limited effect [5-7]. As a result, multiple unique flow patterns have been identified in microfluidic gas-liquid two-phase flow, including bubbly, slug, ring, churn and annular flow [8]. Transport phenomena, such as heat and mass transfer, and reaction kinetics are also significantly improved at the micro-scale due to the increase in surface to volume ratio [9].

A large collection of microchannel hardware is often referred to as Lab-on-a-chip devices, which are directed for use in the biomedical field to perform DNA analysis, enzymatic analysis, proteomics, immunoassaying and point-of-care clinical pathology [10]. Microchannels have also been used to study the flow characteristics of microgel capsules in confined spaces to predict their behaviour and optimize their use for drug delivery in live tissues [11]. Cabral and Hudson [12] used microchannels to develop a microfluidic multicomponent interfacial tensiometer capable of handling a high-throughput of complex fluids. The large surface area to volume ratio of microchannels also makes them ideal for applications that can benefit from tuning of channel wetting properties. Feng et al. [13] used successive flow-focussing microfluidic cross-sections of different wetting properties to first form a typical two-phase slug flow (an emulsion), and later break the emulsion into droplet pairs surrounded by a third liquid continuous phase. The different wetting properties of the channels ensured that in each channel region only one fluid phase preferentially wetted the walls. Takei et al. [14] developed multi-step Laplace valves based on photocatalytic patterning and tuning of the surface wettability of microchannels. The working principle relies on the pressure drop caused by capillary forces imposed on the meniscus at the front of a liquid plug, and is a function of the local contact angle.

There have been significant developments in the area of micro-scale fabrication, which have allowed researchers to construct increasingly more intricate devices. In order to successfully design microfluidic devices it is crucial to fully understand the flow dynamics and physics; this knowledge is generally obtained by performing laboratory experimentation and in a more limited form from numerical modeling. However, large discrepancies still exist in the published data, largely as a result of difficulties and inconsistencies in experimental setup and measurement.

Numerous correlations have been produced that rely on data regression, dimensional analysis or empirical correlations; however they are for the most part based on limited, experimentally accessible information such as the flow pattern observations and various assumptions. It could be possible to extensively improve the accuracy and reliability of such models if the intricacies of the flow fields were known in more detail, which has recently become possible with the advances in the field of multiphase computational fluid dynamics (CFD). With CFD, information about local parameters such as velocity and pressure fields, volumetric mass fractions and interface configurations are easily obtained, whereas in experimental work such data are difficult to measure.

While experimental work on gas-liquid two-phase flow in microchannels is abundant [15,16], that is not the case for numerical modeling. Modeling of multiphase flow phenomena is one of the most complex areas of the field of computational fluid dynamics, and it is a field that is still in continuous development. In recent years the first models that permit interface tracking have become available, in part due to the progress in the field of computing that now allow models that once required highly advanced computing machines to be solved in common personal computers in acceptable periods of time. As a result, the first numerical results have been published on slug formation and flow in microfluidic geometries. Preference in early papers had typically been given to two-dimensional analysis due to its considerably lower computational cost; however the trend has recently been shifting as researchers realize that surface tension physics require full three-dimensionality for correct implementation [2-4]. Nonetheless, in either case the size of the computational geometry must be limited to several channel diameters in length, not enabling modeling of the full length of a microchannel or complex microfluidic networks.

Because of the still novel nature of CFD in the field of microfluidics, and the uncertainties that remain in understanding the fluid dynamic behaviors at this scale, it is interesting to propose a benchmark case that future researchers can use to test their CFD codes or different/newer versions of commercial CFD packages. The present authors have previously conducted a comparison of numerical modeling and experimental work of an identical microchannel T-junction system for the study of gas-liquid slug flow formation [1]. The experiments consisted in producing two-phase flow at the appropriate flow conditions to result in the formation of Taylor slugs in a microfluidic geometry composed of nearly square microchannels (with each side wall in the order of 
$100 \mu \mathrm{m}$ in length) forming a T-junction, whereby liquid entered the main channel, parallel to the outlet flow, while the gas phase entered the side channel, perpendicular to the main and outlet channels. Numerical modeling, using the commercial CFD software FLUENT, which employs the Volume-of-Fluid (VOF) multiphase modeling technique, was performed of the same channel geometry using flow parameters identical to the experimental values. Modeling was entirely done in three-dimensional fashion, in order to fully capture the interfacial tension forces that are so important in the slug break-up process. The computational geometry was also long enough to allow the formation of a few gas slugs in order to better capture the flow and pressure fields in the two-phase region. Within the study several slug flow parameters were measured from numerical and experimental runs that include Taylor slug size and velocity, liquid slug length and velocity, Taylor slug formation frequency, void fraction, cross-sectional air slug coverage and velocity slip. Results were used to construct correlations to predict these parameters based solely on a priori variables, namely the inlet flow rates. This study was unique at the time in that both experiments and fully three-dimensional numerical simulations were performed on the same microfluidic process, something which is not commonly found in the published literature to date.

In this benchmark paper the experimental and numerical methods and results of Santos and Kawaji [1] are described, including detailed data of the relevant variables and parameters. It is hoped that this information can be used by researchers in the field to answer the questions and uncertainties that remain, and to advance the field of microfluidic multiphase computational fluid dynamics.

\section{Description of experimental methods}

\subsection{Experimental apparatus}

Numerical modeling involves predicting the physical phenomena that occur in experiments, therefore it is important to understand in detail how the experiment was designed and conducted; this chapter provides such detail for the system in study. A fairly simple approach was chosen in the design of the experimental apparatus. The fluid delivery method consisted of utilizing two independent syringe pumps to drive the plungers of gastight syringes containing the chosen immiscible phases: air (the gas phase) and water (the liquid phase). The fluids were directed to the microfluidic chip by Teflon tubes that were connected to the syringes by Kel-F hubs and to the microchannel by fitting snugly over short glass capillaries and sealing with epoxy glue. The two-phase flow formation at the T-junction was imaged via a CCD camera, which captured both frame-by-frame images and real-time video. The image stream was processed and recorded in a personal computer by Video Savant software. The two-phase flow outlet was open to the atmosphere, with the water phase dripping from the microchannel by gravity and the air phase released to the environment. The experimental setup is illustrated in Figure 1 .

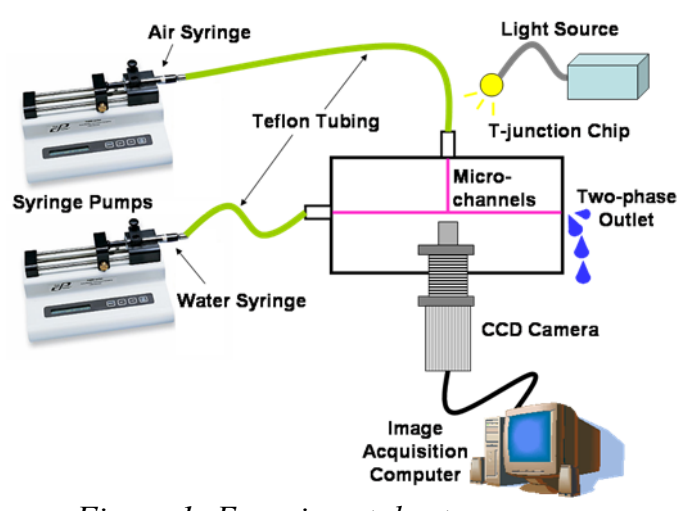

Figure 1: Experimental setup

A list of the components of the experimental setup and their specifications follows:

- Two single-syringe infusion pumps from Cole Palmer, model RK-74900-00; specified accuracy $\pm 0.5 \%$.

- Gas-tight syringes with Teflon luer lock fittings from Hamilton Company, models 1001-TLL (1 ml), 1002-TLL (2.5 ml), 1005-TLL (5 ml) and 1010-TLL (10 ml).

- PTFE tubing with single Kel-F hub from Hamilton Company, model 90613 (gauge 13, 1.93 mm ID, 2.54 mm OD, 12" length).

- Microfluidic T-junction with nominally square $(100 \mu \mathrm{m})$ microchannel embedded in silica glass.

- CCD camera from Pulnix, model TM-1040; 30 frames per second, 1/16,000 s shutter speed, 1,000 x 1,016 pixels resolution.

- Magnifying lens from Mitutoyo model M Plan APO 5; 5x magnification.

- Background light source from Schott-Fostec, model DCR III Plus; 150 watt halogen lamp. 
- Video Savant image capturing software from IO Industries.

- Deionised water.

- Chronograph timer.

The microfluidic T-junction chip was mounted on an acrylic support structure to aid in the positioning of the T-junction in the field of view of the camera and also to protect the delicate glass chip and the glass capillary connections from damage. Figure 2 shows the dimensions of the chip, the microchannels and the locations of the fluid inlets and the outlet. The main microchannel had an overall length of $60 \mathrm{~mm}$ and the water inlet section had a length of $30 \mathrm{~mm}$. The junction of the two channels was exactly in the center of the main channel, $30 \mathrm{~mm}$ from both the water inlet and the outlet. The microchannels were also perfectly centered within the $2 \mathrm{~mm}$ chip thickness. Water entered the channel via the inlet of the main channel, while air entered the channel via the branch line.

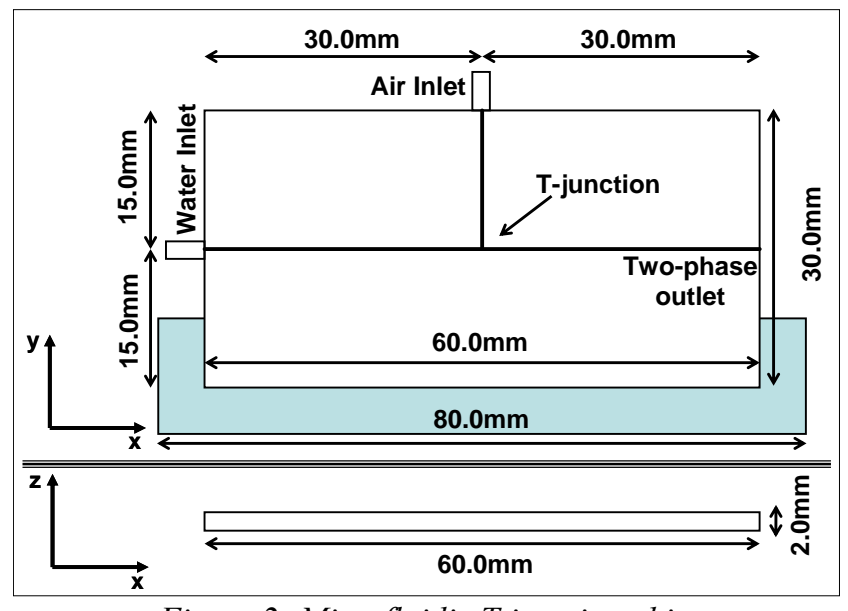

Figure 2: Microfluidic T-junction chip

A close up view of the microchannel T-junction is shown in Figure 3. The channel was produced using femtosecond laser assisted etching, producing straight walls of good surface quality [17,18]. This image was used to measure the precise internal dimensions of the T-junction with the aid of a micrometer slide that provided $10 \mu \mathrm{m}$ markings for calibration (the marking are included in the figure). By drawing lines over the image with drawing software it was possible to compare the length of each line to the length of a line fitted over the calibration markings. It was found that the width of the three microchannels differed slightly. The water inlet channel had a width of $111 \mu \mathrm{m}$, the air inlet channel had a width of $118 \mu \mathrm{m}$ and the outlet channel had a width of $108 \mu \mathrm{m}$. It is also possible to see that the T-junction corners are not perfectly square-angled. The left corner appears to be rounded in shape; an ellipse was drawn to obtain an approximate shape of the channel to build the numerical geometry. The right corner was redrawn as step transition, shown in the figure. These dimensions were used to create the precise computational geometry. The depth of the microchannel was obtained according to a procedure described later.

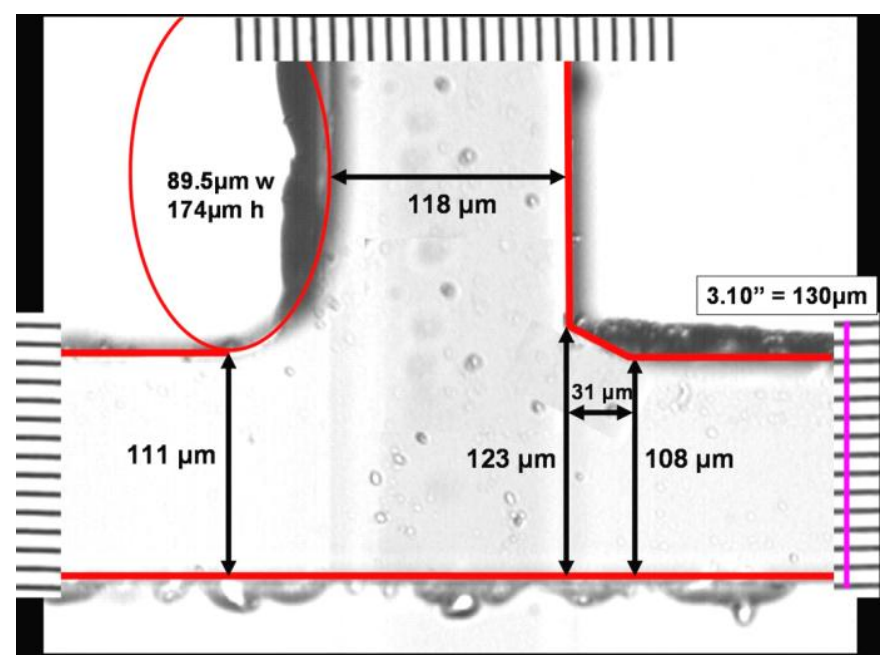

Figure 3: Microfluidic T-junction dimensions 
To confirm that the measurement procedure using the micrometer markings was accurate, a thermocouple wire was introduced into the air inlet channel and its diameter was compared to the channel width. The resulting image is shown in Figure 4. The thermocouple wire had a specified diameter of $76.2 \mu \mathrm{m}$. As can be seen from the image, the width of the channel is also found to be $118 \mu \mathrm{m}$; hence the measurements of the microchannel dimensions in Figure 3 can be considered accurate.

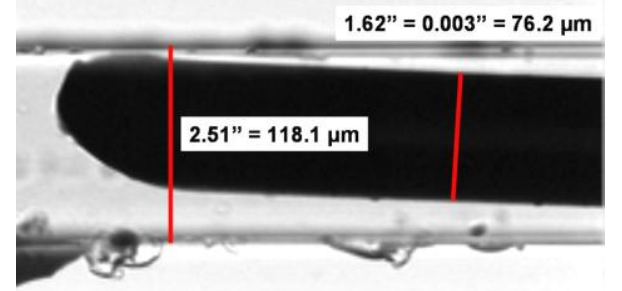

Figure 4: Branch inlet channel width measurement

It was possible to measure the width and length of the microchannels both using a conventional optical microscope and a CCD camera with the aid of a micrometer scale at any location along the T-junction. However, it was only possible to measure the depth of the microchannels (width in the z-direction) from the channel outlet, which may not represent the correct value as the edges of the outlet were slightly worn and also because the depth of the channel at the T-junction and the remaining channel length may differ slightly due to the difficult channel fabrication. In order to obtain a more reliable channel depth value that would more correctly represent the experimental channel geometry in numerical computations, the analytical model presented in Section 2.4 was calibrated with experimentally measured values of Dist $t_{\max }$ and $t_{2}$ (definitions given later), following this procedure:

i. Sixteen experimental runs of varying flow conditions $(12 \mathrm{~g} 8 \mathrm{w}, 3 \mathrm{~g} 4 \mathrm{w}, 2 \mathrm{~g} 4 \mathrm{w}, 2 \mathrm{~g} 2 \mathrm{w}, 12 \mathrm{~g} 12 \mathrm{w}, 20 \mathrm{~g} 12 \mathrm{w}$, $8 \mathrm{~g} 2 \mathrm{w}, 16 \mathrm{~g} 2 \mathrm{w}, 12 \mathrm{~g} 4 \mathrm{w}, 4 \mathrm{~g} 10 \mathrm{w}, 16 \mathrm{~g} 10 \mathrm{w}, 6 \mathrm{~g} 14 \mathrm{w}, 10 \mathrm{~g} 10 \mathrm{w}, 16 \mathrm{~g} 6 \mathrm{w}, 2 \mathrm{~g} 12 \mathrm{w}, 2 \mathrm{~g} 8 \mathrm{w}$; where the numbers preceding letters $\mathrm{g}$ and $\mathrm{w}$ are the gas and water flow rates respectively in $\mathrm{ml} / \mathrm{h}$ ) were performed to obtain experimentally measured values of these two variables (Dist $t_{\max }$ and $t_{2}$ ).

ii. Four analytical runs (using the model of Section 2.4) were performed for each of the sixteen flow conditions, using different values of channel depth $(114,116,117$ and $120 \mu \mathrm{m})$.

iii. The analytically calculated values of Dist $t_{\max }$ and $t_{2}$ were compared to the experimentally determined values; the differences of the analytical and experimental values, expressed in percentages, were recorded for each variable.

iv. The mean average of the two differences (corresponding to Dist $t_{\max }$ and $t_{2}$ ) for each run was plotted as a function of channel depth. This plot is shown in Figure 5.

v. The four data points referring to the same flow condition were fitted to linear relationships $(y=a x+b)$; the value of channel depth that corresponded to a $0 \%$ difference (the point where the fitted line crosses the $\mathrm{x}$-axis) was calculated for each flow condition.

vi. The average of fourteen channel depth values (the highest and lowest values being excluded) was $119 \mu \mathrm{m}$ $\pm 5 \mu \mathrm{m}$. This value was used in all subsequent analytical and numerical runs.

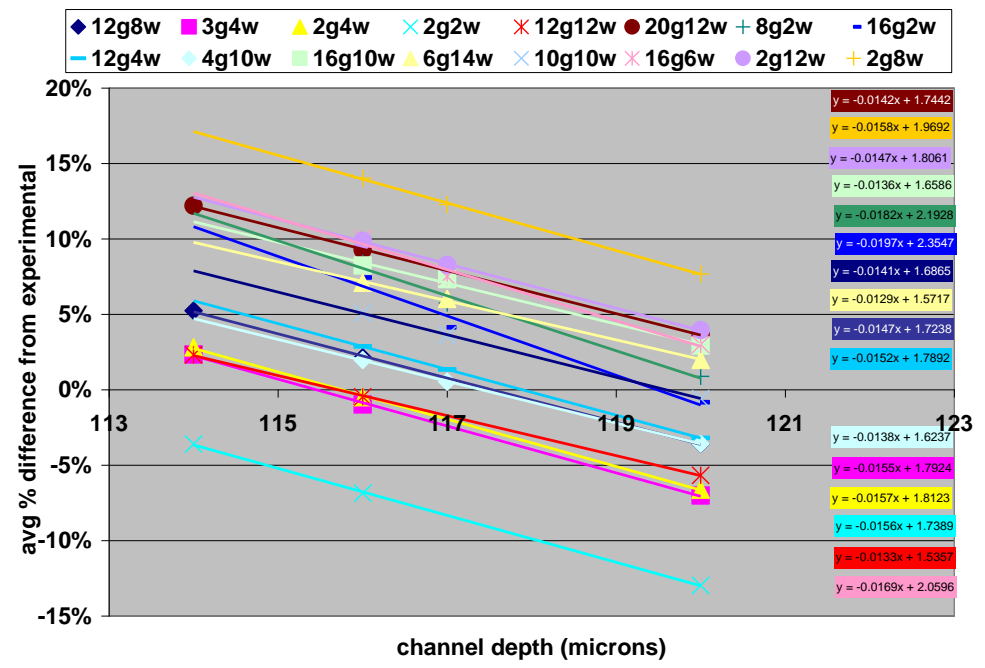

Figure 5: Comparison of analytical and experimental data to determine channel depth 
Lastly, the contact angle $(\theta)$ of the microfluidic T-junction had to be determined to correctly represent the fluid-wall interaction in the numerical model. In the present study, the measurement method described by Hoffman [19] for a meniscus inside a capillary tube was used. Images were taken of air slugs in water at rest inside the present microchannel T-junction. Two parameters were measured from the printed images using a conventional ruler, $R$ and $H$, as indicated in Figure 6, which were used to calculate $\theta$. Ten measurements were made, with values ranging from $30.1^{\circ}$ to $51.3^{\circ}$, with an average of $36.4^{\circ}$. The uncertainty in the value, taken as the standard deviation of the data, is $\pm 3.8^{\circ}$. For numerical simulation runs in the present study the value of $\theta=36^{\circ}$ was used.

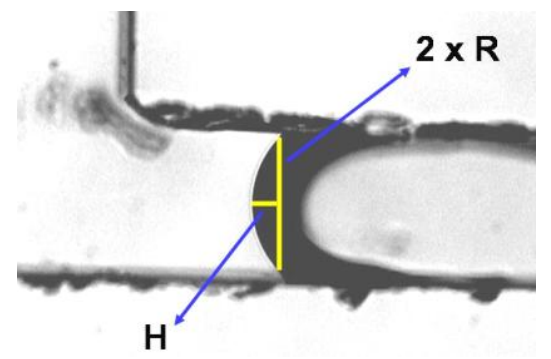

Figure 6: Contact angle measurement in microchannel

\subsection{Experimental procedure}

For each experimental run a specific procedure was used in order to ensure reliable and accurate data collection was performed and that only the flow variables modified from one run to the next affected the outcome of each run. Given that (i) the same microchannel T-junction was used for all experimental runs, (ii) the fluids used were only air and water and (iii) the fluid delivery method was not changed, the only variables in the experiments were: air and water flow rates, and the syringe sizes used. The sizes of the syringes were changed depending on the combination of the fluid flow rates used, as certain experimental limitations, described in detail in Section 2.3, had to be respected. Four syringe sizes were used: 1, 2.5, 5 and $10 \mathrm{ml}$. It is generally desirable to use smaller syringes for microfluidic applications, especially to ensure more smooth fluid delivery from syringe pumps and to reduce the amount of fluid used (important for certain analytical work that use expensive or difficult to obtain fluids). However, the experimental apparatus and procedure used in this work did not allow for the syringe size to be reduced below essentially $1 \mathrm{ml}$ for water delivery and $2.5 \mathrm{ml}$ for air delivery. One reason was that the Teflon tubing had an internal volume of $0.892 \mathrm{ml}$ and it was important to fill this tubing with water and run the experiment for several minutes without having to refill the syringe. The second reason was that the gas phase needed to be compressed in order to gain sufficient pressure to flow into the microchannel, and hence it was necessary for the air flow to last several minutes longer than the actual slug formation period.

The procedure to produce slug flow in the microfluidic T-junction can be divided into three stages: the preparation stage, the start-up period and the slug formation period. The start-up period was required to allow for the fluid pressures and flow rates to equilibrate before the slug formation commenced. During this period the gas phase was compressed to increase static pressure, which allowed it to literally push the water phase out from the branch inlet stream and begin the formation of slugs at the T-junction. The slug formation period was the stage when the slug flow was observed and data was collected.

Preparation Procedure:

1. The flow rates of water and air were selected and entered into the analytical model described in Section 2.4 in order to choose the syringe sizes according to the limiting conditions (Section 2.3) and to find the estimated duration of start-up period (which helped ensure no problems such as leakage, malfunctioning equipment or error in syringe pump setup occurred).

2. The size of the syringes and the desired flow rates were entered on the syringe pump's digital controls.

3. The microfluidic T-junction was cleared of any water contained within by manually blowing air using a syringe into the air inlet.

4. The water syringe was filled with deionised water, mounted on the water syringe pump and connected to the water inlet tubing.

5. The plunger of the air syringe was positioned just past the marking corresponding to the syringe's specified volume. The syringe was mounted on the air syringe pump and connected to the air inlet tubing. The syringe pump was started for a few seconds to allow the pump to engage the syringe; this was done to ensure that during the start-up period the air started flowing and compressing immediately once the syringe pump was activated. 
6. The background light was turned on and the CCD camera was positioned and focused such that it imaged the microchannel T-junction.

Start-up Procedure:

1. The water syringe pump was turned on and water was allowed to fill the water inlet tubing and the microchannel T-junction; during this time the air syringe pump was turned off.

2. At the moment the microchannel was filled with water, as viewed from live images taken by the CCD camera, the air syringe pump was turned on immediately and a timer was initiated.

3. For a period of several minutes, water entered the air inlet tubing and flowed in the direction of the air syringe, while some water also exited the microchannel outlet. At the same time air was being pushed by the syringe, resulting in the air within the tubing and the syringe to become compressed and pressurized.

4. Once the air pressure was high enough, air was able to push the water back towards the microchannel. At this moment the water flow reached its farthest distance along the air inlet tubing; the measurement of this distance, as well as the time indicated by the chronograph, could be compared to the prediction of the analytical model.

5. For several more minutes the water-air interface moved down the air inlet tubing toward the microchannel inlet.

6. When the air-water interface reached the microchannel T-junction, slug formation began immediately. The time indicated by the chronograph was recorded again.

Data Capturing Procedure:

1. Images of the slug formation at the $\mathrm{T}$-junction were acquired by the $\mathrm{CCD}$ camera. 100 image frames were captured at a time (acquisition rate of 30 frames/s, shutter speed of 1/16,000 s, and resolution of $1,000 \mathrm{x}$ 1,016 pixels). Image capturing was done every 20 seconds for the first 2 minutes and every 30 seconds for the next 2 minutes, for a total of 1000 image frames per run.

2. The flow was also filmed by the CCD camera during the run for approximately 5 minutes.

3. Once all data was captured, the syringe pumps were stopped and the apparatus was prepared again for the next run.

\subsection{Limiting flow conditions}

The flow conditions for the experimental runs were restricted to a certain range of values because of limitations of the experimental apparatus used; in particular the sizes of syringes used and the syringe pump rate limits. It was desirable that the experimental runs lasted at least five minutes; the time needed for system start-up is additional to this value. As a result, at high flow rates it is possible to encounter situations where the syringes would run out of fluid, or the pressure drop in the channel would exceed the maximum pressure delivered by the syringe pump, or the water phase would reach the end of the air tubing before the air phase acquired enough pressure to push it back down. It was also important to maintain pumping flow rates at least ten times higher than the minimum syringe pump specifications to ensure smooth flow delivery. To ensure a selected flow condition was appropriate for the experimental system, the analytical model presented in Section 2.4 was run and the resulting values were compared to the limits. The following is a list of all flow limitations:

- Maximum pressure: $18 \mathrm{psi}$

- Maximum flow rates: $125 \mathrm{ml} / \mathrm{h}$ (10 ml syringe), $87 \mathrm{ml} / \mathrm{h}$ ( $5 \mathrm{ml}$ syringe $), 31.7 \mathrm{ml} / \mathrm{h}(2.5 \mathrm{ml}$ syringe $), 13.2$ $\mathrm{ml} / \mathrm{h}(1 \mathrm{ml}$ syringe $)$

- Minimum flow rates: $2 \mathrm{ml} / \mathrm{h}$ (10 $\mathrm{ml}$ syringe), $0.5 \mathrm{ml} / \mathrm{h}$ ( $5 \mathrm{ml}$ syringe $), 0.2 \mathrm{ml} / \mathrm{h}(2.5 \mathrm{ml}$ syringe $), 0.1 \mathrm{ml} / \mathrm{h}$ (1 ml syringe)

- Maximum distance $\left(\right.$ Dist $\left._{10}\right): 27.5 \mathrm{~cm}$

- Maximum run time: $\left(Q_{i n} \times\left(t_{2}+5 \mathrm{~min}\right)\right)$ must be $<V_{\text {syringe }}$

Several analytical runs were performed to produce a flow map that indicated at which flow rates experimental runs were possible, depending on the size of syringe used for the air flow. The map of flow limitations is presented in Figure 7; within the trapezoidal-shaped curves (each for a different syringe volume) experimental runs are possible, while outside them at least one flow limitation is reached and experimental runs are not possible. The volumes of air syringes used in each experimental run are given in Table 4 . 


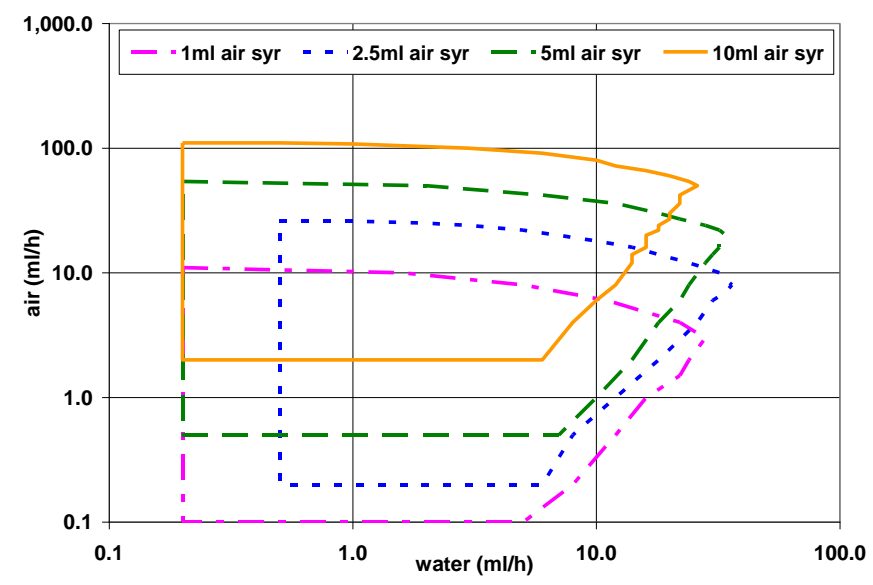

Figure 7: Limits of experimental flow rates

\subsection{Analytical modeling of initial conditions}

An analytical model was developed to ensure that the start-up procedure of experimental runs produced consistent flow conditions. It also allowed for verification that the experimental apparatus was functioning properly, preventing the occurrence of undetectable issues such as a malfunctioning syringe pump, an error in inputting flow conditions to the syringe pump, or a leakage along the fluid inlet lines. The main objective of the analytical model was to predict the period of time $\left(t_{2}\right)$ between the start-up of the air syringe pump and the formation of the first air slug at the T-junction. It also allowed for the determination of the air pressure $\left(P_{\text {air }, \text { final }}\right)$ and air density $\left(\rho_{\text {air }}\right)$ at the moment of the first air slug formation. The model functions primarily by equilibrating pressures at the T-junction during the start-up period, which is achieved with the use of the following set of equations:

$$
\begin{aligned}
& \Delta P_{\text {out }, i}=\Delta P_{\text {branchi }} \\
& \Delta P_{\text {out }, i}=\frac{32 \mu L_{\text {out }} U_{\text {out }, i}}{D_{h, \text { out }}^{2}} \\
& \Delta P_{\text {branch } i}=\frac{32 \mu L_{\text {branch }} U_{\text {branchi } i}}{D_{h, \text { branch }}^{2}}+\rho_{w} g L_{\text {branch }}+\left(\frac{101325 \times V_{Y T}}{V_{\text {free }, i}}-101,325\right)+ \\
& 0.108 \rho_{w} g \times \sin \left[\min \left(\frac{\text { Dist }_{i}}{0.108}, \frac{0.17}{0.108}\right)\right] \\
& Q_{\text {water,branchi } i}=Q_{\text {water, } \text { in }}-Q_{\text {water, } \text { out }, i} \\
& \text { Dist }_{i+1}=\frac{\operatorname{avg}\left(Q_{\text {water,branchi }}+Q_{\text {water,branchi+1 } 1}\right) \times \omega_{I, I I}}{A_{\text {tube }}}+\text { Dist }_{i} \\
& V_{\text {free }, i+1}=V_{\text {free }, i}-\left\lfloor\operatorname{avg}\left(Q_{\text {water,branchi }}+Q_{\text {water,branchi }+1}\right)+Q_{\text {air }, \text { in }}\right\rfloor \times \varpi_{I, I I} \\
& \Delta P_{\text {out }, 10}=\Delta P_{\text {out }}=\frac{32 \mu L_{\text {out }} Q_{\text {water }, \text { in }}}{D_{h, \text { out }}^{2} A_{\text {out }}}
\end{aligned}
$$

Equation (1)

Equation (2)

Equation (3)

Equation (4)

Equation (5)

Equation (6)

Equation (7)

The objective of this analytical model is to find the values of the pressure drop $(\triangle P)$ for water that flows through the outlet channel and out of the microchannel (Equation (2), Munson et al. 1998), and through the air inlet channel (branch) and into the air inlet tubing (Equation (3)) that equal each other (Equation (1)) as a function of time. $V_{Y T}$ is the volume of the syringe $(1,2.5,5$ or $10 \mathrm{ml})$ plus the volume of the tubing $(0.892 \mathrm{ml})$. $V_{\text {free }}$ is the volume of tubing plus syringe occupied by air. $L_{\text {branch }}$ and $L_{\text {out }}$ are, respectively, the gas inlet microchannel length and outlet microchannel length, both of which equal $3 \mathrm{~cm}$. Dist $t_{i}$ is the distance from the point where the syringe tube connects to the T-junction to the location of the air-water interface within the tubing. The sine function is used to account for the curvature of the tubing and the minimum function is used to locate the maximum hydraulic pressure at the point where the tubing straightens out. The flow rates $(Q)$ of water to both channels were determined using Equation (4). A goal-seeking procedure is used to solve this set of equations, whereby the value of $Q_{\text {water, out }, i}$ is changed until Equation 1 is satisfied. A time stepping procedure (step index $i$ ) is employed that tracks the water-air interface moving upstream into the air inlet tubing until the water flow eventually stops flowing into the branch line and flows back down into the T-junction. Ten time steps 
$(\omega)$ are used for the upward flow (subscript $I$ ) and ten more for the downward flow (subscript $I I$ ). Equation (5) is used to advance the interface one time step and Equation (6) is used to track the change in volume of the air phase as it compresses within the syringe and tubing. At each time step the goal-seeking procedure is repeated again. After ten time steps Equation (7) is applied; if not satisfied, the time step value $\left(\omega_{I}\right)$ is changed until the equality is satisfied (up to a residual value allowed). At this point the water-air interface reaches the maximum distance along the tubing $\left(\right.$ Dist $_{10}=$ Dist $\left._{\max }\right)$ at time $t_{1}$. Also at this point, the compressed air phase has enough pressure to start pushing the water phase back into the T-junction. Another ten time steps (step value $\omega_{I I}$ ) are then performed until the interface returns back to the T-junction inlet (Dist $\left.{ }_{20}=0\right)$, and another five time steps until the interface reaches the T-junction $\left(\right.$ Dist $\left._{25}=-1.5 \mathrm{~cm}\right)$.

The final air density value can be calculated using Equation (8), and the respective air pressure with Equation (9). Other useful values obtained that can be compared to values measured experimentally are $t_{l}$ (Equation (10)) and $t_{2}$ (Equation (11)).

$$
\begin{aligned}
& \rho_{\text {air }}=\frac{\left(P_{\text {air,gaugefinal }}\right)}{8.314 \times 293} \\
& P_{\text {air,final }}=\frac{101,325 \times V_{Y T}}{V_{Y T}-Q_{\text {air,in }} \times t_{2}} \\
& t_{1}=10 \times \omega_{I} \\
& t_{2}=10 \times \omega_{I I}+t_{1}
\end{aligned}
$$

\section{Equation (8)}

Equation (9)

Equation (10)

Equation (11)

\section{Description of numerical methods}

\subsection{Computational geometry and meshing}

Numerical methods compute continuous mathematical functions in a finite number of data points (nodes) distributed along a computational domain. If the data points are sparsely spaced the accuracy of the model will decrease and the results will deviate from the real solution (the experimentally expected behaviour). On the other hand, if the nodes are packed too closely, the number of data points becomes very large and the computational cost becomes prohibitive. As a result, it is important to select an appropriate mesh resolution that balances these two extremes. In this study, the computational mesh was created using Gambit 2.3 software, which is an application developed by Fluent Incorporated (now part of ANSYS). The same mesh resolution $(5.67 \mu \mathrm{m})$ was applied to the entire computational geometry (i.e. no mesh refinement in specific regions) to ensure the flow behaviour would be accurately captured independent of channel location. A preliminary mesh refinement study was performed to ensure the mesh resolution was sufficient to produce mesh-independent results. In a first study the values of mesh spacing used were: $2.25 \mu \mathrm{m}, 4.50 \mu \mathrm{m}, 9.00 \mu \mathrm{m}$, and $18.00 \mu \mathrm{m}$. It was found that $4.5 \mu \mathrm{m}$ produced satisfactory results. Upon further investigation it was found that a mesh size of $5.67 \mu \mathrm{m}$ produced nearly identical results to those of $4.5 \mu \mathrm{m}$, while reducing the total number of computational nodes by half, thereby reducing computational time significantly. Therefore $5.67 \mu \mathrm{m}$ mesh size was used in the remainder of this work. The steps to produce a computational mesh for the microfluidic T-junction can be summarized as follows:

- Draw the outline of the microfluidic channel (according to the dimensions shown in Figure 3), viewed from the side (x-y place) in 2D to create a face;

- Mesh the face using quadrilateral elements and the pave scheme (creates a slightly unstructured quadrilateral mesh that better covers the T-junction geometry than the submap structured grid);

- To create a 3D geometry, a vertex is created at coordinate $(0,0, z)$, where $\mathrm{z}$ is the width of the geometry in the third-dimension (or half-width for symmetrical models);

- Create an edge by connecting the newly created vertex to the vertex at location $(0,0,0)$;

- Mesh the edge using the same mesh spacing used for the face;

- Create the meshed 3D computational volume by sweeping the 2D face along the edge, together with the mesh;

- Apply boundary conditions to the inlets (velocity inlet), outlet (pressure outlet) and the symmetry $x$-y face at coordinate z (symmetry);

- Export mesh to FLUENT.

Figure 8 shows a close-up view of the symmetry plane $(\mathrm{z}=59.5 \mu \mathrm{m})$ of the computational mesh used for the numerical runs. It is possible to see how the paved meshing scheme produces quadrilateral cells that are more structured in the channel regions and less structured in the T-junction center. The source of loss of structure 
appears to be the ellipsoidal shape used to outline the left corner of the T-junction, which causes FLUENT to sub-map that region differently from the straight channels. Nonetheless, this meshing scheme did not present any problems related to convergence of modeling data. The symmetry plane contained of a total of 14,338 computational cells/facets with an average lattice length of $5.67 \mu \mathrm{m}$.

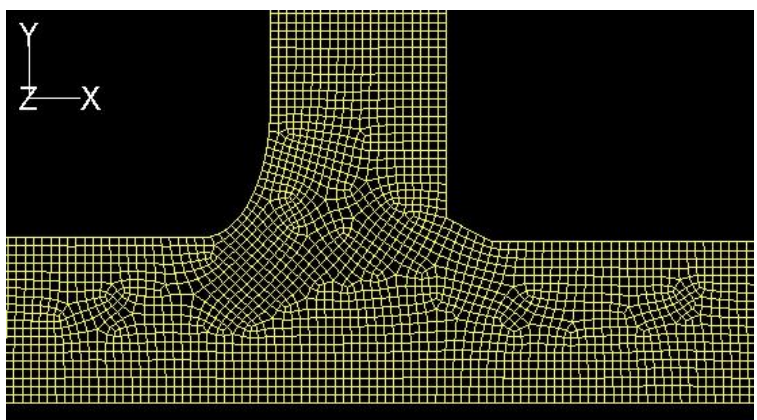

Figure 8: Computational T-junction mesh cross-section close-up (5.67 um paved)

The full computational volume for the microfluidic $\mathrm{T}$-junction is shown in Figure 9 along with the dimensions of the channels; the volume shown is mirrored at the symmetry plane, only half the volume was modelled, assuming slug flow is characteristically symmetric. The computational geometry used had a total length of $3,885 \mu \mathrm{m}$. The lengths of the water inlet channel and the air inlet channel were chosen according to the necessary lengths required for full laminar flow to develop. The length of the inlet channels must be larger than the entrance length $\left(L e=0.06 \cdot D_{h} \cdot R e\right)$ predicted from laminar flow theory for the highest flow rates to be modeled with the channel. For the maximum flow rate of water used $(36 \mathrm{ml} / \mathrm{h})$ the corresponding entrance length is $588 \mu \mathrm{m}$, or 5.3 channel hydraulic diameters $\left(D_{h}\right)$. Therefore the inlet channel for water was made 6 diameters $(666 \mu \mathrm{m})$ in length. The entrance length for the highest flow rate of air is $51 \mu \mathrm{m}$, which is less than one channel hydraulic diameter, so the air inlet channel was made 2 diameters long plus the length of the curved corner $(309 \mu \mathrm{m})$. The outlet channel was made long enough so that in most numerical runs more than one gas slug would form before the slug reached the end of the channel. The symmetrical computational geometry contained a total of 143,380 computational cells.

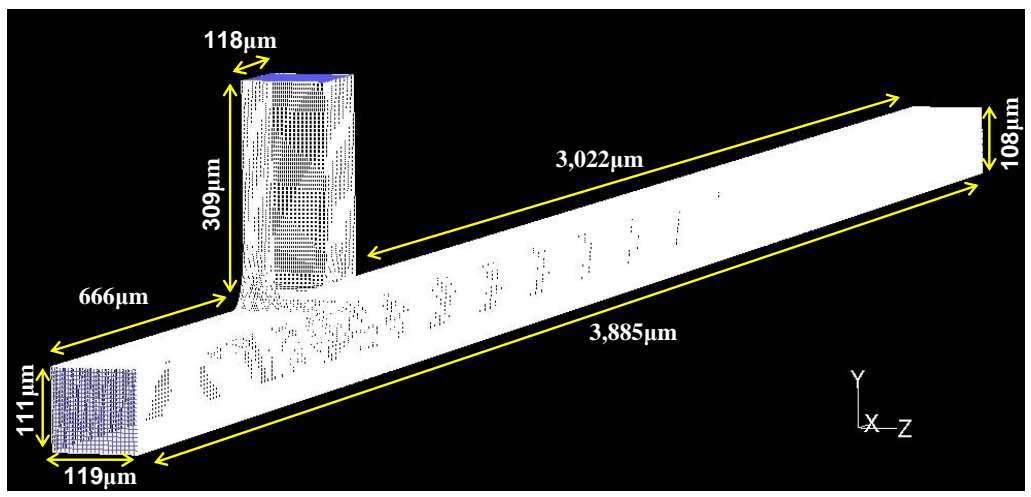

Figure 9: Computational T-junction mesh volume (5.67 $\mu$ m paved)

In Figure 10 the water inlet channel mesh is shown in two forms: facets and nodes. Facets are useful for displaying contour plots as they take the average of the four nodes associated with them providing a smoothed transition in the color plots. The nodes are the specific locations where values of variables are attributed to by the CFD software. It can be seen that the distribution of nodes or facets is the same in both the $\mathrm{x}$ and $\mathrm{y}$ directions. This would appear to contradict expectations as the channel height and width are not exactly equal $(111 \mu \mathrm{m}$ versus $119 \mu \mathrm{m}$ respectively) and a constant mesh spacing of $5.67 \mu \mathrm{m}$ was applied. However, Gambit requires that all facets have the same lattice length, and hence rounding takes place. For example, 59.5/5.67 equals 10.49 (half width due to symmetry), and 111/5.67 equals 19.58. The resulting mesh is rounded to give 20 facets in the y-direction and 10 facets (half-symmetry) in the z-direction. As a result the mesh for the water inlet channel has a spacing of $5.95 \mu \mathrm{m}$ in the $\mathrm{z}$-direction and $5.55 \mu \mathrm{m}$ in the $\mathrm{y}$-direction. 


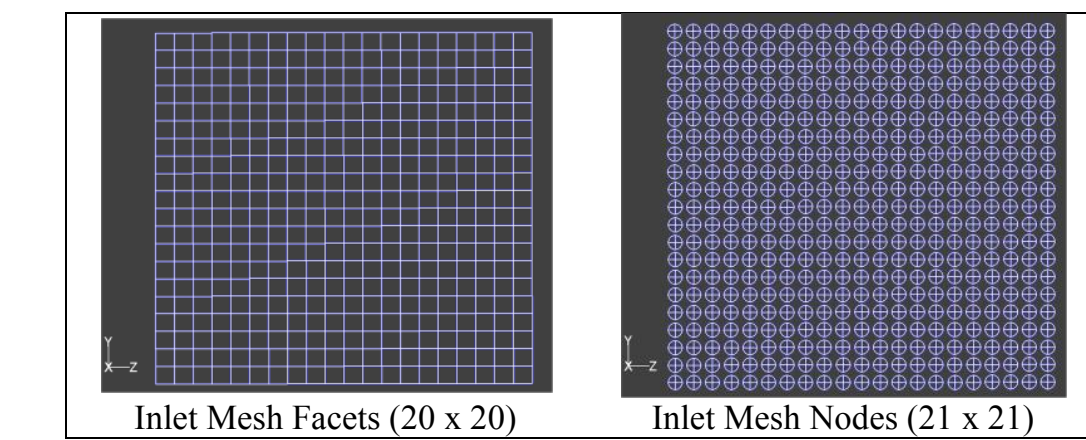

Figure 10: Computational water inlet channel mesh (mirrored at symmetry plane)

\subsection{Numerical Modeling Procedure}

In this section the numerical modeling approaches used in the FLUENT 6.2 CFD software by Santos and Kawaji [1] for solution of the multiphase VOF model are outlined. Details of the FLUENT VOF model such as governing equations are given in [1] in accordance with [20]. The following are the principal steps in setting up, running and analyzing the model:

Grid: The computational mesh prepared in Gambit was read into the FLUENT CFD software, which was operated using the 3DDP mode (three-dimensional double precision), and was scaled by a factor of $10^{-6}$.

Solver: A segregated axi-symmetric time-dependent unsteady solver was used. The VOF model was chosen as the multiphase flow model and the geometric interpolation scheme was used for interface interpolation, along with the implicit body force formulation and a Courant number of 0.25. For discretization the PRESTO! (Pressure Staggering Options) scheme was used for pressure interpolation, the PISO (Pressure-Implicit with Splitting of Operators) scheme was used for pressure-velocity coupling, and the second-order up-wind differencing scheme was used for the momentum equation. Under-relaxation factors were set to values of 1 for pressure, density and body forces, and 0.7 for momentum.

Materials and Phases: From the FLUENT materials database air and water-liquid were chosen as the fluids; the density of air was adjusted as needed to match analytical model results. Air was designated as the primary phase and water was the secondary phase. Wall adhesion was turned on and a surface tension value of $73.5 \mathrm{dyn} / \mathrm{cm}$ was inputted.

Boundary Conditions: For the inlets, the velocity inlet boundary condition was used, while pressure outlet boundary condition was used for the outlet and the symmetry boundary condition was assigned to the symmetry face. For the inlet boundaries inlet velocities were entered and the water volume fractions at the boundaries were set to 1 for the main inlet and 0 for the branch inlet. For the outlet boundary the backflow volume fraction was set to 1 and the gauge pressure was set to zero Pascal. For the wall boundary condition the contact angle value was inputted.

Initialization: The flow field was initialized, setting all velocities, pressures and volume fractions to zero. This caused the entire channel geometry to be filled with air initially. In order not to have to model water filling the entire main channel, the flow field in the main channel was modified using the patching technique. The computational cells in the main channel were marked and the water volume fraction was set to a value of 1 for all these cells (i.e. all remaining cells in the branch channel were filled with air).

Iteration: The residuals of the continuity equation and the $\mathrm{x}, \mathrm{y}$ and $\mathrm{z}$ momentum equations were monitored during numerical computation and the convergence criterion for the model to move on to the next time step was chosen as 0.0001 for each equation. The fixed time stepping method was chosen and a time step value of $1.6 \times 10^{-6} \mathrm{~s} / \mathrm{step}$ was used. The maximum number of iterations per time step was set to 30 (most numerical runs converged within approximately 15 iterations or less). The number of time steps was selected according to the flow rates and ranged from 2,000 to 10,000.

Data analysis: After each numerical run was completed the data was analyzed to produce useful qualitative and quantitative results. In order to quantitatively identify flow parameters such as the gas slug velocity, the gas slug length and volume, the distance between gas slugs and the location of the centroid of gas slugs, a user-defined function (UDF) was developed and used. This UDF was written in C programming language and was compiled and executed within FLUENT. The velocity of gas slugs $\left(v_{\mathrm{S}}\right)$ was calculated by volume-weighted averaging of the axial velocity $\left(v_{x}\right)$ of the gas phase contained within the gas slug according to Equation (12). The volume of gas slugs $\left(V_{S}\right)$ was calculated by the summation of the gas phase volume (volume of cell, $V_{\text {cell }}$, times volume fraction of gas in that cell, $\Omega_{G}$ ) contained in the range of computation (cellrange) according to Equation (13). The lengths of gas and liquid slugs ( $L_{S}$ and $L_{C}$ respectively) were measured between the noses of the gas slugs. 


$$
\begin{gathered}
v_{S}=\frac{\sum_{i=1}^{\text {cellrange }} \Omega_{G, i} \cdot V_{\text {cell }, i} \cdot v_{x, i}}{\sum_{i=1}^{\text {cellrange }} \Omega_{G, i} \cdot V_{\text {cell }, i}} \\
V_{S}=\sum_{i=1}^{\text {cellrange }} \Omega_{G, i} \cdot V_{\text {cell }, i}
\end{gathered}
$$

Equation (13)

\section{Flow Conditions}

A total of 27 experimental runs and simulations were performed with varying flow rates. Water flow rates ranged from 2 to $36 \mathrm{ml} / \mathrm{h}$ and air flow rates ranged from 0.9 to $40 \mathrm{ml} / \mathrm{h}$. The corresponding inlet superficial velocities for both fluids are as follows: water inlet velocities ranged from $0.042 \mathrm{~m} / \mathrm{s}$ to $0.757 \mathrm{~m} / \mathrm{s}$; air inlet velocities ranged from $0.018 \mathrm{~m} / \mathrm{s}$ to $0.791 \mathrm{~m} / \mathrm{s}$. Figure 11 shows the range of flow rates utilized; Table 1 provides detailed information on the flow conditions, including the calculated initial air density and pressure based on the analytical model.

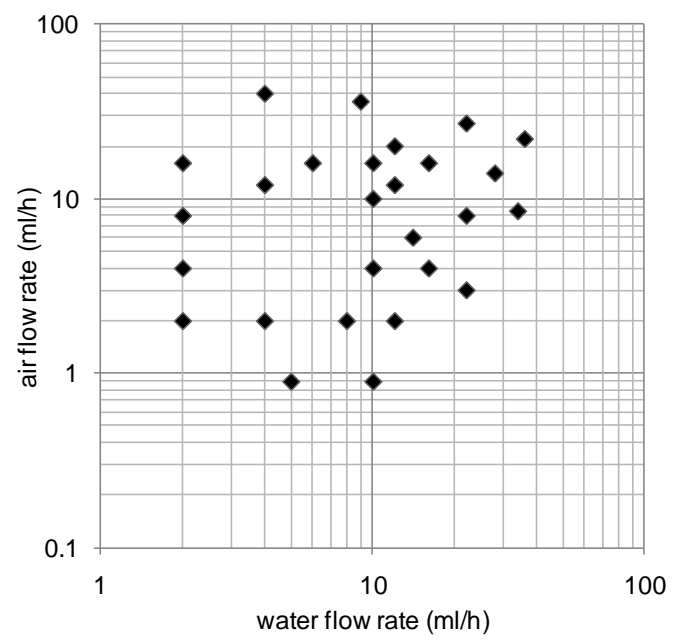

Figure 11: Flow rate map 
Table 1: Flow conditions

\begin{tabular}{|c|c|c|c|c|c|c|}
\hline Run & $Q_{w}(\mathrm{ml} / \mathrm{h})$ & $Q_{g}(\mathrm{ml} / \mathrm{h})$ & $U_{w}(\mathrm{~m} / \mathrm{s})$ & $U_{g}(\mathrm{~m} / \mathrm{s})$ & $\rho_{\text {gas }}\left(\mathrm{kg} / \mathrm{m}^{3}\right)$ & $P_{\text {gas }}(\mathrm{kPa})$ \\
\hline $2 \mathrm{w} 2 \mathrm{~g}$ & 2 & 2 & 0.042 & 0.040 & 1.269 & 106.7 \\
\hline $2 \mathrm{w} 4 \mathrm{~g}$ & 2 & 4 & 0.042 & 0.079 & 1.273 & 107.0 \\
\hline $2 \mathrm{w} 8 \mathrm{~g}$ & 2 & 8 & 0.042 & 0.158 & 1.275 & 107.2 \\
\hline $2 \mathrm{w} 16 \mathrm{~g}$ & 2 & 16 & 0.042 & 0.317 & 1.278 & 107.5 \\
\hline $4 \mathrm{w} 2 \mathrm{~g}$ & 4 & 2 & 0.084 & 0.040 & 1.322 & 111.2 \\
\hline $4 \mathrm{w} 12 \mathrm{~g}$ & 4 & 12 & 0.084 & 0.237 & 1.348 & 113.3 \\
\hline $4 \mathrm{w} 40 \mathrm{~g}$ & 4 & 40 & 0.084 & 0.791 & 1.358 & 114.2 \\
\hline $5 \mathrm{w} 0.9 \mathrm{~g}$ & 5 & 0.9 & 0.105 & 0.018 & 1.322 & 111.2 \\
\hline $6 \mathrm{w} 16 \mathrm{~g}$ & 6 & 16 & 0.126 & 0.317 & 1.421 & 119.5 \\
\hline $8 \mathrm{w} 2 \mathrm{~g}$ & 8 & 2 & 0.168 & 0.040 & 1.404 & 118.1 \\
\hline $9 \mathrm{w} 36 \mathrm{~g}$ & 9 & 36 & 0.189 & 0.712 & 1.552 & 130.5 \\
\hline $10 \mathrm{w} 0.9 \mathrm{~g}$ & 10 & 0.9 & 0.210 & 0.018 & 1.419 & 119.3 \\
\hline $10 \mathrm{w} 4 \mathrm{~g}$ & 10 & 4 & 0.210 & 0.079 & 1.482 & 124.6 \\
\hline $10 \mathrm{w} 10 \mathrm{~g}$ & 10 & 10 & 0.210 & 0.198 & 1.531 & 128.7 \\
\hline $10 \mathrm{w} 16 \mathrm{~g}$ & 10 & 16 & 0.210 & 0.317 & 1.555 & 130.8 \\
\hline $12 \mathrm{w} 2 \mathrm{~g}$ & 12 & 2 & 0.252 & 0.040 & 1.484 & 124.8 \\
\hline $12 \mathrm{w} 12 \mathrm{~g}$ & 12 & 12 & 0.252 & 0.237 & 1.630 & 137.1 \\
\hline $12 \mathrm{w} 20 \mathrm{~g}$ & 12 & 20 & 0.252 & 0.396 & 1.670 & 140.4 \\
\hline $14 \mathrm{w} 6 \mathrm{~g}$ & 14 & 6 & 0.294 & 0.119 & 1.602 & 134.7 \\
\hline $16 \mathrm{w} 4 \mathrm{~g}$ & 16 & 4 & 0.336 & 0.079 & 1.612 & 135.5 \\
\hline $16 \mathrm{w} 16 \mathrm{~g}$ & 16 & 16 & 0.336 & 0.317 & 1.787 & 150.3 \\
\hline $22 \mathrm{w} 3 \mathrm{~g}$ & 22 & 3 & 0.463 & 0.059 & 1.705 & 143.4 \\
\hline $22 \mathrm{w} 8 \mathrm{~g}$ & 22 & 8 & 0.463 & 0.158 & 1.819 & 153.0 \\
\hline $22 \mathrm{w} 27 \mathrm{~g}$ & 22 & 27 & 0.463 & 0.534 & 2.024 & 170.2 \\
\hline $28 \mathrm{w} 14 \mathrm{~g}$ & 28 & 14 & 0.589 & 0.277 & 2.063 & 173.5 \\
\hline $34 \mathrm{w} 8.5 \mathrm{~g}$ & 34 & 8.5 & 0.715 & 0.168 & 2.081 & 186.3 \\
\hline $36 \mathrm{w} 22 \mathrm{~g}$ & 36 & 22 & 0.757 & 0.435 & 2.604 & 219.0 \\
\hline & & & & & & \\
\hline
\end{tabular}

\section{Results and Comparison}

\subsection{Flow parameters examined}

In examining the results of the present work, the approach taken was to investigate the effects of input variables on the resulting parameters obtained from numerical simulation. For the numerical runs presented in this chapter, the following parameters were kept constant:

- surface tension

- contact angle

- types of fluids

- fluid properties (except air density)

- types of boundaries

- channel geometry

- meshing

- solver settings

This leaves the only parameters being modified between runs to be:

- inlet air and water flow rates

- air density $\left(\rho_{\text {gas }}\right)$

- number of time steps

The predicted parameters from the numerical simulation are many in number; however only a select few are valuable in the characterization of slug flow in microchannels. The following is a list of all parameters obtained from numerical results:

- Length of gas slug $\left(L_{S}\right)$

- Volume of gas slug $\left(V_{S}\right)$

- Velocity of gas slug $\left(v_{S}\right)$

- Frequency of gas slug break-up $\left(f_{S}\right)$

- Length of continuous phase slug $\left(L_{C}\right)$

- Void Fraction $(\varepsilon)$

- Velocity slip ( $S$ and $\left.v_{x} / U_{\text {out }}\right)$

- Cross-sectional gas slug area $\left(A_{S}\right)$

- $\quad$ Static pressure $\left(P_{S T}\right)$

The length of the gas slug $\left(L_{S}\right)$ is defined as the distance between the front and rear noses of a gas slug. Similarly, the length of the continuous phase $\left(L_{C}\right)$ is defined as the distance between the rear nose of one gas slug and the front nose of the subsequent gas slug (i.e. the span on the water phase between gas slugs). The slug 
break-up frequency $\left(f_{S}\right)$ is defined as the number of occurrences of gas slugs per unit time. Practically, this parameter can be measured by taking the inverse of the time it takes for two gas slugs to flow past the same point along the microchannel. Another form of obtaining the same measurement is by having two points of reference that move with the gas slug, instead of the stationary one in the previous case, and that are positioned at a similar point on both gas slugs (at each center of gravity or at each advancing nose, for instance). In this case the distance between the two points is measured and the ratio between the slug velocity and the distance yields the frequency. The void fraction $(\varepsilon)$ is defined as the ratio of the volume of a single gas slug by the volume occupied by a slug unit (consecutive gas and liquid slugs). The velocity slip $(S)$ is defined as the ratio of the gas slug velocity over the liquid plug velocity $\left(v_{S} v_{C}\right)$. Lastly, in order to investigate how the gas slug fills the microchannel (if completely or with liquid film or with liquid only in corners) it is desirable to know the area of a plane perpendicular to the fluid flow in the microchannel at the gas slug centroid that is taken up by the gas phase; this area is termed the cross-sectional gas slug area $\left(\mathrm{A}_{\mathrm{S}}\right)$.

The number of parameters measured experimentally was smaller due to: (i) difficulties in measurement of certain parameters experimentally $\left(V_{S}\right.$ and $A_{S}$ ); and (ii) lack of instrumentation (pressure transducers for $P_{S T}$, higher speed CCD camera for $v_{\mathrm{S}}, L_{C}$ and $f_{S}$ ). As a result the following data are available from the experimental study:

- Length of gas slug $\left(L_{S, \text { exp }}\right)$

- Void Fraction $\left(\varepsilon_{\text {exp }}\right)$

- Velocity slip $\left(S_{\text {exp }}\right)$

\subsection{Benchmark data}

As the objective of this paper is to provide data and methodology for a CFD benchmark case, and an article has already been published on the interpretation of these results in regards to the field of multiphase microfluidics [1], this section will limit to providing the measured and calculated numerical and experimental data and highlighting the key observations in their comparison.

Table 2 shows the numerical data obtained directly from FLUENT simulations with the use of UDF's for all 28 runs. The velocity of the gas slugs are shown for all three coordinates $(x, y, z)$; as can be seen, only the $x$ direction value is of most relevance, while $y$ - and $z$-direction values are essentially zero given the slug nearly completely occupies the microchannel cross-sectional area (expect for thin liquid films). The time $(t)$ shown is the time counted from the start of the simulation until the gas $\operatorname{slug}(\mathrm{s})$ fully formed and detached into the outlet channel. The last two columns show the number of gas slugs fully formed and detached at this time, and the number (\#) of the slug characterized (counted starting from the first slug formed). Whenever possible, the first or last slug to form was not used for characterization to ensure quasi-steady-state behavior. 
Table 2: Numerical simulation measured data

\begin{tabular}{|c|c|c|c|c|c|c|c|c|}
\hline Run & $v_{S, x}(\mathrm{~m} / \mathrm{s})$ & $v_{S, y}(\mathrm{~m} / \mathrm{s})$ & $v_{S, z}(\mathrm{~m} / \mathrm{s})$ & $V_{S}(\mathrm{~nL})$ & $L_{S}(\mu \mathrm{m})$ & $t(\mathrm{~s})$ & Slug \# & Slugs \\
\hline $2 \mathrm{w} 2 \mathrm{~g}$ & 0.086 & $8.6 \mathrm{E}-04$ & $3.2 \mathrm{E}-04$ & 5.18 & 435.7 & 0.0096 & 1 & 1 \\
\hline $2 \mathrm{w} 4 \mathrm{~g}$ & 0.129 & $1.4 \mathrm{E}-04$ & $6.4 \mathrm{E}-05$ & 7.76 & 641.9 & 0.0080 & 1 & 1 \\
\hline $2 \mathrm{w} 8 \mathrm{~g}$ & 0.216 & $1.4 \mathrm{E}-05$ & $1.2 \mathrm{E}-04$ & 12.92 & 1044.5 & 0.0092 & 1 & 1 \\
\hline $2 \mathrm{w} 16 \mathrm{~g}$ & 0.409 & $9.9 \mathrm{E}-05$ & $-2.5 \mathrm{E}-04$ & 22.39 & 1861.5 & 0.0064 & 1 & 1 \\
\hline $4 \mathrm{w} 2 \mathrm{~g}$ & 0.130 & $-1.3 \mathrm{E}-04$ & $3.2 \mathrm{E}-05$ & 3.70 & 324.3 & 0.0096 & 1 & 1 \\
\hline $4 \mathrm{w} 12 \mathrm{~g}$ & 0.354 & $-1.1 \mathrm{E}-03$ & $1.5 \mathrm{E}-04$ & 10.11 & 846.2 & 0.0036 & 1 & 1 \\
\hline $4 \mathrm{w} 40 \mathrm{~g}$ & 1.016 & $8.0 \mathrm{E}-06$ & $-2.4 \mathrm{E}-05$ & 22.50 & 1912.4 & 0.0028 & 1 & 1 \\
\hline $5 \mathrm{w} 0.9 \mathrm{~g}$ & 0.127 & $1.5 \mathrm{E}-04$ & $-3.8 \mathrm{E}-05$ & 2.76 & 250.7 & 0.0096 & 1 & 1 \\
\hline $6 \mathrm{w} 16 \mathrm{~g}$ & 0.500 & $-5.4 \mathrm{E}-05$ & $-2.4 \mathrm{E}-04$ & 8.66 & 749.3 & 0.0048 & 2 & 2 \\
\hline $8 \mathrm{w} 2 \mathrm{~g}$ & 0.217 & $1.4 \mathrm{E}-03$ & $1.2 \mathrm{E}-03$ & 2.80 & 256.1 & 0.0080 & 1 & 1 \\
\hline $9 \mathrm{w} 36 \mathrm{~g}$ & 1.041 & $4.7 \mathrm{E}-05$ & $-4.0 \mathrm{E}-05$ & 8.58 & 755.2 & 0.0028 & 2 & 3 \\
\hline $10 \mathrm{w} 0.9 \mathrm{~g}$ & 0.235 & $-1.3 \mathrm{E}-04$ & $-2.2 \mathrm{E}-05$ & 2.19 & 210.5 & 0.0080 & 1 & 1 \\
\hline $10 \mathrm{w} 4 \mathrm{~g}$ & 0.307 & $-9.1 \mathrm{E}-04$ & $5.1 \mathrm{E}-04$ & 3.11 & 284.0 & 0.0096 & 2 & 3 \\
\hline $10 \mathrm{w} 10 \mathrm{~g}$ & 0.456 & $9.1 \mathrm{E}-03$ & $-1.8 \mathrm{E}-04$ & 4.51 & 405.0 & 0.0032 & 2 & 2 \\
\hline $10 \mathrm{w} 16 \mathrm{~g}$ & 0.590 & $-8.1 \mathrm{E}-05$ & $-2.3 \mathrm{E}-04$ & 5.76 & 511.1 & 0.0048 & 2 & 3 \\
\hline $12 \mathrm{w} 2 \mathrm{~g}$ & 0.304 & $7.8 \mathrm{E}-04$ & $2.2 \mathrm{E}-03$ & 2.35 & 222.0 & 0.0064 & 1 & 1 \\
\hline $12 \mathrm{w} 12 \mathrm{~g}$ & 0.544 & $-2.7 \mathrm{E}-05$ & $-2.1 \mathrm{E}-04$ & 4.37 & 397.5 & 0.0048 & 2 & 3 \\
\hline $12 \mathrm{w} 20 \mathrm{~g}$ & 0.728 & $-2.6 \mathrm{E}-04$ & $1.9 \mathrm{E}-04$ & 5.78 & 516.5 & 0.0040 & 2 & 3 \\
\hline $14 \mathrm{w} 6 \mathrm{~g}$ & 0.454 & $3.0 \mathrm{E}-04$ & $-4.0 \mathrm{E}-04$ & 2.99 & 284.0 & 0.0064 & 2 & 3 \\
\hline $16 \mathrm{w} 4 \mathrm{~g}$ & 0.451 & $-6.6 \mathrm{E}-05$ & $-4.9 \mathrm{E}-04$ & 2.38 & 232.9 & 0.0064 & 2 & 3 \\
\hline $16 \mathrm{w} 16 \mathrm{~g}$ & 0.728 & $2.9 \mathrm{E}-04$ & $-6.4 \mathrm{E}-05$ & 4.03 & 369.5 & 0.0040 & 3 & 4 \\
\hline $22 \mathrm{w} 3 \mathrm{~g}$ & 0.564 & $3.8 \mathrm{E}-04$ & $-7.6 \mathrm{E}-04$ & 1.83 & 187.6 & 0.0040 & 1 & 2 \\
\hline $22 \mathrm{w} 8 \mathrm{~g}$ & 0.682 & $-7.8 \mathrm{E}-05$ & $-2.3 \mathrm{E}-04$ & 2.42 & 238.7 & 0.0048 & 3 & 4 \\
\hline $22 \mathrm{w} 27 \mathrm{~g}$ & 1.143 & $1.9 \mathrm{E}-04$ & $1.9 \mathrm{E}-05$ & 3.83 & 363.7 & 0.0024 & 3 & 5 \\
\hline $28 \mathrm{w} 14 \mathrm{~g}$ & 0.969 & $-8.3 \mathrm{E}-04$ & $-4.3 \mathrm{E}-04$ & 2.51 & 250.4 & 0.0024 & 3 & 4 \\
\hline $34 \mathrm{w} 8.5 \mathrm{~g}$ & 0.970 & $1.2 \mathrm{E}-04$ & $-5.8 \mathrm{E}-04$ & 1.72 & 182.3 & 0.0032 & 3 & 4 \\
\hline $36 \mathrm{w} 22 \mathrm{~g}$ & 1.379 & $1.1 \mathrm{E}-03$ & $-3.9 \mathrm{E}-03$ & 1.69 & 188.1 & 0.0016 & 3 & 5 \\
\hline
\end{tabular}

Table 3 presents relevant parameters for microfluidic flow analysis calculated from the numerical results. These include gas slug formation frequency $\left(f_{S}\right)$, void fraction $(\varepsilon)$, velocity slip $(S)$, gas slug velocity to outlet superficial velocity ratio $\left(v_{S, x} / U_{\text {out }}\right)$, and gas slug cross-section area $\left(A_{S}\right.$, expressed as a percentage of the outlet channel cross-section area, $\left.A_{c h}\right)$. The water slug length $\left(L_{C}\right)$ is measured in a similar way to $L_{S}$ previously described, except for representing the distance between two successive fully formed gas slugs. The values shown are average lengths of the water slugs formed, except for those marked by $*$, where a single water slug was measured. The homogenous void fraction $(\beta)$ is a useful value for comparison against $\varepsilon$. It is typical for microfluidic flow to display $\varepsilon<\beta$, due to gas slug velocity slip (i.e. $S>1$ or $v_{S, x} / U_{\text {out }}>1$ ) [1]. It was not possible, evidently, to calculate $L_{C}, f_{S}, \varepsilon$ and $S$ for numerical runs that formed a single gas slug. The following set of equations defines these calculated parameters:

$$
\begin{aligned}
& \beta=\frac{Q_{g}}{Q_{g}+Q_{w}} \\
& f_{S}=\frac{v_{S}}{L_{S}+L_{C}}=\frac{Q_{g}}{V_{S}} \\
& U_{\text {out }}=\frac{Q_{w}+Q_{g}}{A_{\text {out }}} \\
& S=\left(\frac{Q_{g} \times(1-\varepsilon)}{Q_{w} \times \varepsilon}-1\right) \times 100 \\
& \varepsilon=\frac{V_{S}}{\left(L_{S}+L_{C}\right) \times A_{\text {ch }}} \\
& A_{S}=\frac{\sum \text { Volume_fraction_values }}{380}
\end{aligned}
$$

Some useful relationships for prediction of slug formation, based on a priori known variables $\left(U_{\text {out }}\right.$ and $\left.\beta\right)$, are given below based on curve fitting of the produced numerical data.

$$
\begin{aligned}
& v_{S}=1.072 \times U_{\text {out }}^{1.037} \\
& f_{S}=207.51 \times \mathrm{e}^{(2.14 \times \text { Uout })}
\end{aligned}
$$


Table 3: Numerical simulation calculated results

\begin{tabular}{|c|c|c|c|c|c|c|c|}
\hline Run & $L_{C, a v g}(\mu \mathrm{m})$ & $f_{S}(\mathrm{~Hz})$ & $\beta$ & $\varepsilon$ & $S$ & $v_{S, x} / U_{\text {out }}$ & $A_{S}(\%)$ \\
\hline $2 \mathrm{w} 2 \mathrm{~g}$ & - & - & 0.50 & - & - & 1.00 & 100.0 \\
\hline $2 \mathrm{w} 4 \mathrm{~g}$ & - & - & 0.67 & - & - & 1.00 & 100.0 \\
\hline $2 \mathrm{w} 8 \mathrm{~g}$ & - & - & 0.80 & - & - & 1.00 & 100.0 \\
\hline $2 \mathrm{w} 16 \mathrm{~g}$ & - & - & 0.89 & - & - & 1.05 & 96.7 \\
\hline $4 \mathrm{w} 2 \mathrm{~g}$ & - & - & 0.33 & - & - & 1.00 & 100.0 \\
\hline $4 \mathrm{w} 12 \mathrm{~g}$ & - & - & 0.75 & - & - & 1.02 & 96.7 \\
\hline $4 \mathrm{w} 40 \mathrm{~g}$ & - & - & 0.91 & - & - & 1.07 & 93.3 \\
\hline $5 \mathrm{w} 0.9 \mathrm{~g}$ & - & - & 0.15 & - & - & 1.00 & 100.0 \\
\hline $6 \mathrm{w} 16 \mathrm{~g}$ & $224^{*}$ & 514 & 0.73 & 0.69 & 1.19 & 1.05 & 96.7 \\
\hline $8 \mathrm{w} 2 \mathrm{~g}$ & - & - & 0.20 & - & - & 1.01 & 98.4 \\
\hline $9 \mathrm{w} 36 \mathrm{~g}$ & 147 & 1,153 & 0.80 & 0.74 & 1.41 & 1.07 & 93.3 \\
\hline $10 \mathrm{w} 0.9 \mathrm{~g}$ & - & - & 0.08 & - & - & 1.00 & 100.0 \\
\hline $10 \mathrm{w} 4 \mathrm{~g}$ & 578 & 356 & 0.29 & 0.28 & 1.03 & 1.02 & 98.4 \\
\hline $10 \mathrm{w} 10 \mathrm{~g}$ & $328^{*}$ & 621 & 0.50 & 0.48 & 1.09 & 1.05 & 95.0 \\
\hline $10 \mathrm{w} 16 \mathrm{~g}$ & 254 & 771 & 0.62 & 0.59 & 1.13 & 1.05 & 96.7 \\
\hline $12 \mathrm{w} 2 \mathrm{~g}$ & - & - & 0.14 & - & - & 1.00 & 98.4 \\
\hline $12 \mathrm{w} 12 \mathrm{~g}$ & 314 & 765 & 0.50 & 0.48 & 1.09 & 1.05 & 96.7 \\
\hline $12 \mathrm{w} 20 \mathrm{~g}$ & 243 & 958 & 0.63 & 0.59 & 1.15 & 1.05 & 95.6 \\
\hline $14 \mathrm{w} 6 \mathrm{~g}$ & 527 & 559 & 0.30 & 0.29 & 1.07 & 1.05 & 96.7 \\
\hline $16 \mathrm{w} 4 \mathrm{~g}$ & 737 & 466 & 0.20 & 0.19 & 1.06 & 1.04 & 96.7 \\
\hline $16 \mathrm{w} 16 \mathrm{~g}$ & 291 & 1,102 & 0.50 & 0.47 & 1.11 & 1.05 & 96.7 \\
\hline $22 \mathrm{w} 3 \mathrm{~g}$ & $931 *$ & 504 & 0.12 & 0.13 & 0.94 & 1.04 & 96.7 \\
\hline $22 \mathrm{w} 8 \mathrm{~g}$ & 507 & 914 & 0.27 & 0.25 & 1.08 & 1.05 & 93.3 \\
\hline $22 \mathrm{w} 27 \mathrm{~g}$ & 204 & 2,014 & 0.55 & 0.53 & 1.11 & 1.08 & 93.3 \\
\hline $28 \mathrm{w} 14 \mathrm{~g}$ & 374 & 1,553 & 0.33 & 0.31 & 1.10 & 1.07 & 93.3 \\
\hline $34 \mathrm{w} 8.5 \mathrm{~g}$ & 527 & 1,367 & 0.20 & 0.19 & 1.07 & 1.06 & 93.3 \\
\hline $36 \mathrm{w} 22 \mathrm{~g}$ & 195 & 3,599 & 0.38 & 0.34 & 1.17 & 1.10 & 81.3 \\
\hline & & & & & & & \\
\hline
\end{tabular}

In Table 4 the experimentally measured data are given. Also shown are analytical model results for the velocity of the gas phase in the gas inlet channel at the beginning of slug formation $\left(U_{\text {branch }}\right)$ and the time $\left(t_{2}\right)$ elapsed during the experimental start-up phase. As can be seen the time is not directly a function of either the water or air flow rates. In fact it is a product of balancing the force of the water flow with the force of the pressurizing air and the rate of air pressurization. 
Table 4: Experimental data

\begin{tabular}{|c|c|c|c|c|c|c|c|}
\hline Run & $\begin{array}{c}V_{\text {syringe,air }} \\
(\mathrm{ml})\end{array}$ & $\varepsilon_{\text {exp }}$ & $S_{\text {exp }}$ & $\begin{array}{c}L_{S, \exp } \\
(\mu \mathrm{m})\end{array}$ & $\begin{array}{c}U_{\text {branch }} \\
(\mathrm{m} / \mathrm{s})\end{array}$ & $\begin{array}{c}t_{2} \\
(\mathrm{~min})\end{array}$ & $\begin{array}{c}\left(\Delta P_{f} / \Delta Z\right)_{T P} \\
(\mathrm{KPa} / \mathrm{m})\end{array}$ \\
\hline $2 \mathrm{w} 2 \mathrm{~g}$ & 10 & 0.05 & 17.3 & 819 & 0.022 & 16.4 & - \\
\hline $2 \mathrm{w} 4 \mathrm{~g}$ & 2.5 & 0.08 & 21.7 & 761 & 0.030 & 2.7 & - \\
\hline $2 \mathrm{w} 8 \mathrm{~g}$ & 10 & 0.06 & 59.8 & 714 & 0.032 & 4.5 & - \\
\hline $2 \mathrm{w} 16 \mathrm{~g}$ & 10 & 0.09 & 77.2 & 754 & 0.035 & 2.3 & - \\
\hline $4 \mathrm{w} 2 \mathrm{~g}$ & 10 & 0.02 & 21.8 & 627 & 0.033 & 28.9 & - \\
\hline $4 \mathrm{w} 12 \mathrm{~g}$ & 10 & 0.09 & 31.3 & 595 & 0.067 & 5.8 & - \\
\hline $4 \mathrm{w} 40 \mathrm{~g}$ & 10 & 0.16 & 52.8 & 805 & 0.077 & 1.8 & - \\
\hline $5 \mathrm{w} 0.9 \mathrm{~g}$ & 2.5 & 0.03 & 6.25 & 475 & 0.021 & 19.9 & - \\
\hline $6 \mathrm{w} 16 \mathrm{~g}$ & 10 & 0.15 & 14.6 & 471 & 0.103 & 6.2 & - \\
\hline $8 \mathrm{w} 2 \mathrm{~g}$ & 5 & 0.09 & 2.40 & 405 & 0.045 & 25.0 & - \\
\hline $9 \mathrm{w} 36 \mathrm{~g}$ & 10 & 0.18 & 17.8 & 598 & 0.178 & 4.1 & 1,137 \\
\hline $10 \mathrm{w} 0.9 \mathrm{~g}$ & 2.5 & 0.01 & 8.09 & 319 & 0.021 & 34.1 & - \\
\hline $10 \mathrm{w} 4 \mathrm{~g}$ & 5 & 0.14 & 2.48 & 402 & 0.084 & 16.5 & 726 \\
\hline $10 \mathrm{w} 10 \mathrm{~g}$ & 10 & 0.14 & 6.38 & 341 & 0.136 & 13.9 & - \\
\hline $10 \mathrm{w} 16 \mathrm{~g}$ & 10 & 0.19 & 6.76 & 663 & 0.161 & 9.2 & 954 \\
\hline $12 \mathrm{w} 2 \mathrm{~g}$ & 5 & 0.10 & 1.48 & 312 & 0.048 & 33.2 & - \\
\hline $12 \mathrm{w} 12 \mathrm{~g}$ & 10 & 0.04 & 25.4 & 352 & 0.168 & 14.2 & 1,046 \\
\hline $12 \mathrm{w} 20 \mathrm{~g}$ & 10 & 0.26 & 4.83 & 410 & 0.203 & 9.1 & 1,131 \\
\hline $14 \mathrm{w} 6 \mathrm{~g}$ & 5 & 0.24 & 1.36 & 366 & 0.129 & 14.6 & 1,065 \\
\hline $16 \mathrm{w} 4 \mathrm{~g}$ & 2.5 & 0.16 & 1.29 & 286 & 0.099 & 12.8 & 1,118 \\
\hline $16 \mathrm{w} 16 \mathrm{~g}$ & 10 & - & - & 395 & 0.240 & 13.3 & 1,447 \\
\hline $22 \mathrm{w} 3 \mathrm{~g}$ & 2.5 & 0.15 & 0.78 & 228 & 0.077 & 19.9 & - \\
\hline $22 \mathrm{w} 8 \mathrm{~g}$ & 2.5 & 0.28 & 0.95 & 341 & 0.193 & 8.6 & 1,633 \\
\hline $22 \mathrm{w} 27 \mathrm{~g}$ & 5 & 0.57 & 0.91 & 357 & 0.395 & 5.3 & - \\
\hline $28 \mathrm{w} 14 \mathrm{~g}$ & 5 & 0.45 & 0.61 & 344 & 0.322 & 10.5 & 2,195 \\
\hline $34 \mathrm{w} 8.5 \mathrm{~g}$ & 2.5 & - & - & 228 & 0.223 & 10.1 & 2,379 \\
\hline $36 \mathrm{w} 22 \mathrm{~g}$ & 5 & 0.50 & 0.62 & 221 & 0.499 & 7.9 & - \\
\hline & & & & & & & \\
\hline
\end{tabular}

\subsection{Discussion on data comparison}

A quick inspection of the data in Tables 3 and 4 highlights differences between the numerically predicted void fraction and velocity slip and the experimentally measured values. A comparison is made of the void fraction values in Figure 12, in which the data was divided between runs where the inlet water flow rate was greater or smaller than $13 \mathrm{ml} / \mathrm{h}$. It is interesting to note that when $Q_{w}>13 \mathrm{ml} / \mathrm{h}$ the data have better agreement. In Table 1 it can be seen that the main difference between runs above and below this threshold is the air density achieved during the start-up phase. Higher values of $Q_{w}$ produced larger air inlet pressures, independent of the gas flow rate. This means that when $Q_{w}$ is small, the air may not be sufficiently pressurized to maintain twophase flow regime, and so the gas slug formation is intermittent, thereby producing lower void fractions than expected. 


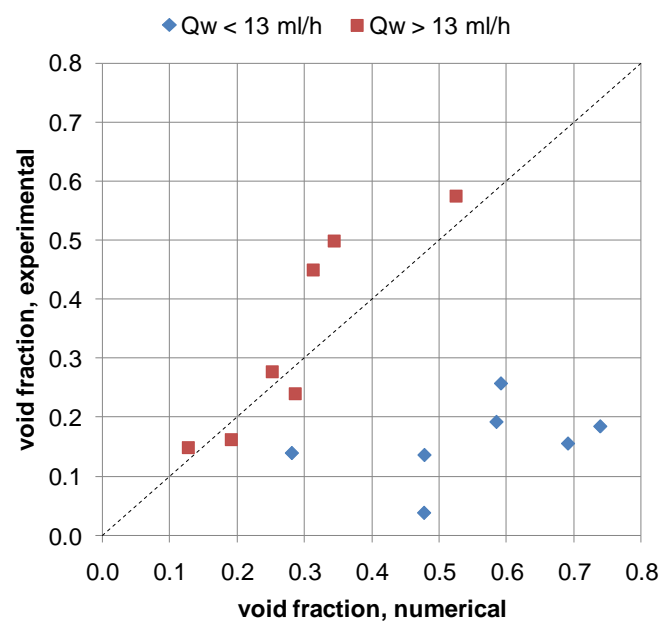

Figure 12: Comparison of numerical and experimental void fraction values

It may also be possible to explain the discrepancy of void fraction values based on possible pressure fluctuations that occur in the gas inlet channel that are not captured, or modeled, in the numerical simulation. These pressure fluctuations can be caused by gas phase compressibility during the gas slug formation process (deformation, squeezing, pinching and detachment phases), which may not be fully captured in the incompressible VOF model used in this study. Moreover, continuing pressurization of the inlet channel, leading to increasing air density, air static pressure at the inlet and gas inlet velocity, may also be responsible for the time-dependent nature of microfluidic gas-liquid two-phase flow which is not modeled in the short time (milliseconds) captured by numerical simulation. Similarly, depressurization of the inlet gas flow can also occur. The analytical model assumes the pressure drop along the outlet channel is due to solely water flow at $U_{\text {out }}$ velocity. Once two-phase flow commences, the pressure drop in the outlet channel changes (most typically it is lowered). As a result less resistive force to flow takes place, and the inlet gas flow becomes over-pressurized for the required steady-state conditions. Consequently the gas inlet air volume expands, increasing the true gas inlet flow rate beyond the modeled value. One possible phenomenon that can be excluded is the intermittent retreat of the gas-liquid interface into the branch channel after slug formation. It was experimentally observed that the interface remains at the T-junction throughout the experiment duration after the first slug formation.

Besides pressure fluctuations, another theory to explain the discrepancies between experimental and numerical values lays in the slug flow hydrodynamics in the outlet channel. Because of the dimensions of the microchannel used, the flow is strictly laminar. This implies that the flow velocity profile is parabolic, with the highest velocity at the center of the channel and a stationary thin film at the channel walls. Because the gas slug flows in the center of the channel surrounded by a liquid film, it can be expected that its average velocity will be higher than the liquid average velocity. Hence velocity slip takes place. This is predicted by the numerical simulation (Table 3), but the values are significantly lower than the experimental data (Table 4). The discrepancy may be explained by the pressure fluctuations already discussed, in combination with a mismatch of the true gas flow rate with the superficial value delivered by the syringe pump, and an underestimation by the numerical model of the thickness of the liquid film (due to lack of mesh refinement along the channel walls, inaccurate contact angle value used or inaccurate fluid-wall interaction model in FLUENT for microfluidic flow). Further discussions on this issue can be found in [1] for the present system, and further data is presented by Kawahara et al. $[8,21]$ on this topic.

A similar comparison of numerical and experimental data is given in Figure 13 for the gas slug length. Better agreement is also seen for runs where $Q_{w}>13 \mathrm{ml} / \mathrm{h}$, though in general the agreement is improved compared to the case of void fraction. 


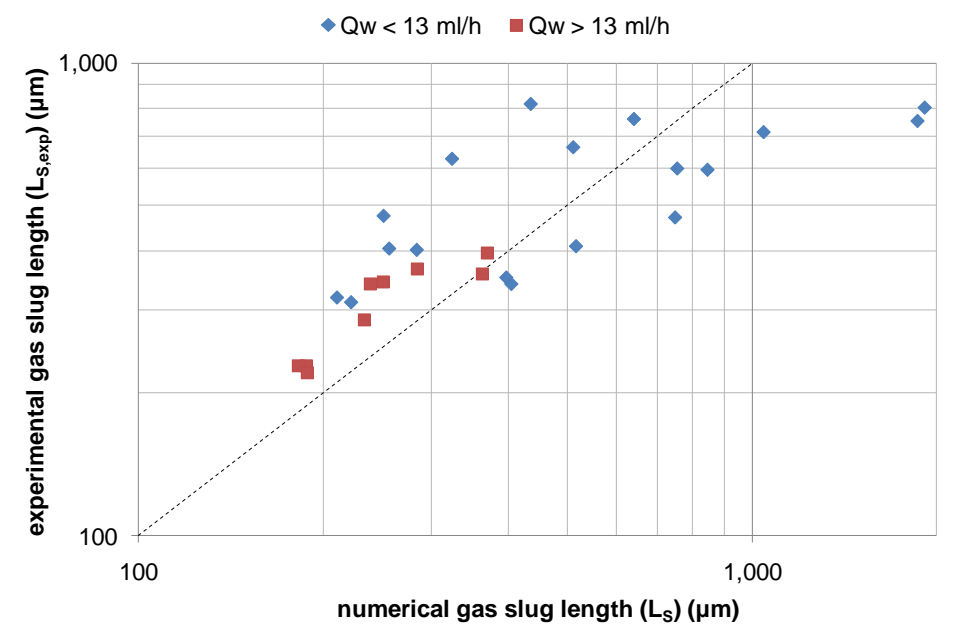

Figure 13: Comparison of numerical and experimental gas slug length values

\subsection{Two-Phase Frictional Pressure Drop}

The two-phase frictional pressure drop is an important parameter in the engineering field that allows for the appropriate selection and design of pumping power required for particular fluid systems applications. In the field of microfluidics, pressure losses are usually quite high due to the small channel diameters encountered. Therefore, it is important to know the expected pressure losses when designing microfluidic systems. For single phase applications, the pressure drop in microchannels is easily obtained from conventional correlations used for laminar flow in pipes, the most common of which is the Hagen-Poiseuille equation (Equation (23)).

$$
\left(\frac{d P}{d Z}\right)_{S P}=\frac{32 \mu U}{D_{h}^{2}}
$$

Equation (23)

Finding the frictional pressure drop for two-phase flow is not as simple as the single phase case. Much work has been done in the literature to correlate experimental results at varying length scales. The correlation that has been most widely accepted both for conventional channels and in the field of microfluidics is that proposed by Lockhart and Martinelli [22] (Equation (24)), which was developed based on the assumption of separated flow. The correlation makes use of a parameter called the two-phase frictional multiplier, $\varphi_{L}^{2}$, which relates the frictional pressure drop of the liquid phase flowing alone in the channel, with that of the two-phase flow.

$$
\left(\frac{d P}{d Z}\right)_{T P}=\varphi_{L}^{2}\left(\frac{d P}{d Z}\right)_{L}
$$

Equation (24)

The two-phase frictional multiplier is correlated, in turn, with the Lockhart-Martinelli parameter $(X)$, whose squared value is essentially the ratio between the single phase pressure drops of liquid over gas, calculated as if they were flowing in the channel alone (Equation (25)). A correlation for $\varphi_{L}{ }^{2}$, in turn, has been proposed by Chisholm [23] that includes a coefficient $C$ (Equation (26)), which has been shown to range in value from 5 to 20 for flows in larger channels depending on whether the flow is laminar or turbulent. Kawahara et al. [8], who performed experiments on two-phase flow in a $100 \mu \mathrm{m}$ diameter circular microchannel capillary with a reducer inlet, obtained a Chisholm coefficient value of 0.24 .

$$
\begin{aligned}
X^{2} & =\left(\frac{d P}{d Z}\right)_{L} /\left(\frac{d P}{d Z}\right)_{G} \\
\varphi_{L}^{2} & =1+\frac{C}{X}+\frac{1}{X^{2}}
\end{aligned}
$$

Equation (25)

Equation (26)

In the present study, the objectives with regards to frictional pressure drop were to find out if the numerical simulation results agreed with the Lockhart-Martinelli equation, and to find the value of the Chisholm coefficient that best fits the predictions. In order to obtain numerical values of two-phase frictional pressure drop, static pressure data were extracted from the numerical results. For each numerical run, the value of static pressure was measured at two points along the microchannel length, downstream from the T-junction. To obtain accurate results, the two points were chosen to be exactly midway between a particular gas slug and the following and preceding slugs (that is, in the middle of the liquid slug). Because of the need for more than two water slugs, one before and the other after the gas slug, only numerical runs that produced at least three gas slugs were able to provide data on the pressure drop; a total of 11 runs (Table 4). The two-phase frictional pressure drop was calculated according to Equation (27). Furthermore, single-phase pressure drops were calculated using the inlet 
superficial velocity of each phase for each run, according to the Hagen-Poiseuille equation. The data was then fitted to the Chisholm correlation, using the least square errors method, to find the Chisholm coefficient $(C)$.

$$
\left(\frac{d P}{d Z}\right)_{T P} \cong\left(\frac{\Delta P}{\Delta Z}\right)_{T P}=\frac{P_{x_{1}}-P_{x_{2}}}{x_{2}-x_{1}}
$$

Equation (27)

The resulting values, along with the curve representing the $C$ coefficient found, are plotted in Figure 14 . The two-phase frictional pressure drop ranged from a minimum value of $726 \mathrm{kPa} / \mathrm{m}$ (run $10 \mathrm{w} 4 \mathrm{~g}$ ) to a maximum of $2,378 \mathrm{kPa} / \mathrm{m}$ (run $34 \mathrm{w} 8.5 \mathrm{~g}$ ). The largest value of the two-phase frictional multiplier obtained was 2.40 (run $9 \mathrm{w} 36 \mathrm{~g}$ ), and the smallest value was 1.33 (run $16 \mathrm{w} 4 \mathrm{~g}$ ). It can be observed that the data points agree very well with the Lockhart-Martinelli correlation, as all data points fall on the fitted curve for a value of $C=5.0$.

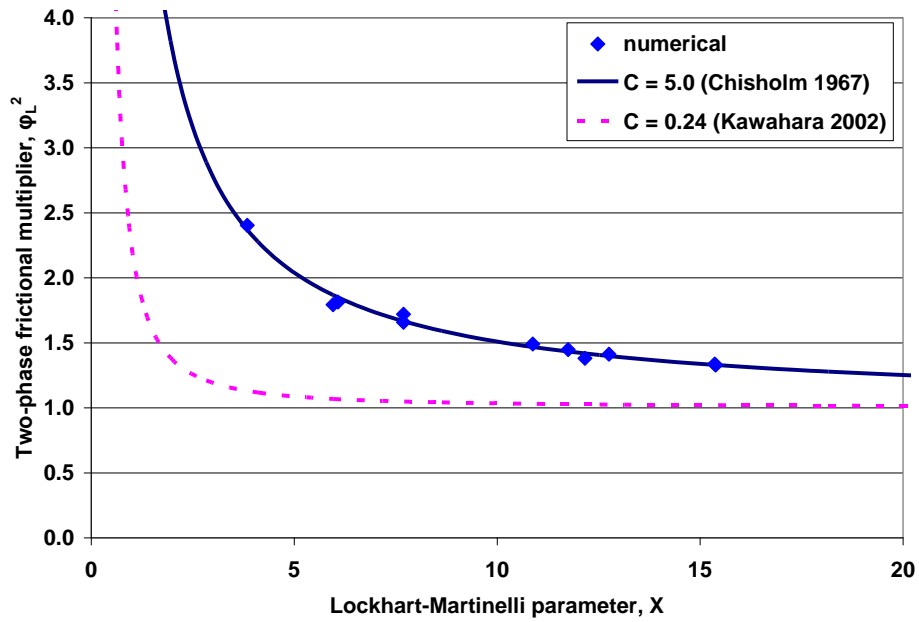

Figure 14: Two-phase frictional pressure drop by Lockhart-Martinelli correlation

Also plotted in Figure 14 is the curve obtained for a $C$ value of 0.24 , as was measured experimentally by Kawahara et al. [8]. That curve predicts considerably lower values of the two-phase frictional multiplier. Therefore, the two-phase frictional pressure drop measured by Kawahara et al. [8] was lower than the values presently obtained from the numerical simulation. In fact, over the range of $X$ values tested in the present runs (approximately 5 to 15 ), the data of [8] indicated values of $\varphi_{L}^{2}$ very close to 1.0 , meaning that the measured twophase frictional pressure drop is virtually equal to the single-phase liquid pressure drop. This would appear to be incorrect since when the gas and liquid phases flow downstream from the T-junction, it is expected that the actual liquid velocity to be in the order of $U_{\text {out }}$, which is always significantly more than the inlet superficial velocity of the liquid. If the actual liquid velocity is increased, it would be expected that the frictional pressure drop in the two-phase region would be significantly higher, as found numerically here. The explanation that may fit the data of [8] is that the gas has a very high velocity slip, penetrating and passing by the liquid phase, which remains flowing at a superficial velocity similar to its inlet value. This high-slip two-phase flow was characteristic of the reducer inlet geometry with an inlet line having a much larger diameter than the microchannel. In the present numerical simulation, velocity slip was rather low and thus the results agree much better with Chisholm's prediction.

\subsection{Further consideration from CFD modeling}

The ability of FLUENT to provide the value of static pressure at any point along the microchannel geometry was also used to track changes in the pressure at the gas inlet channel. The objective was to observe any particularities that could identify intricacies behind the gas slug break-up mechanism. The numerical measurement was made at a point in the center of the gas inlet channel, located $254 \mu \mathrm{m}$ upstream of the Tjunction, where the air flow was fully developed laminar, undisturbed by the dynamics of the slug formation, except for the pressure changes.

Static pressure profiles are presented in Figure 15 for four representative runs: $2 \mathrm{w} 16 \mathrm{~g}, 6 \mathrm{w} 16 \mathrm{~g}, 10 \mathrm{w} 16 \mathrm{~g}$ and $16 \mathrm{w} 16 \mathrm{~g}$, for which the air flow rate was kept constant and only the water flow rate was changed. It is also useful to view Figure 16, which shows the static pressure contours, to better understand the trend in the static pressure data. The increasing water flow rate caused the air slug length to decrease and the frequency of air slug formation to increase. It can be seen that for each air slug that forms, a spike in the static pressure occurs. 


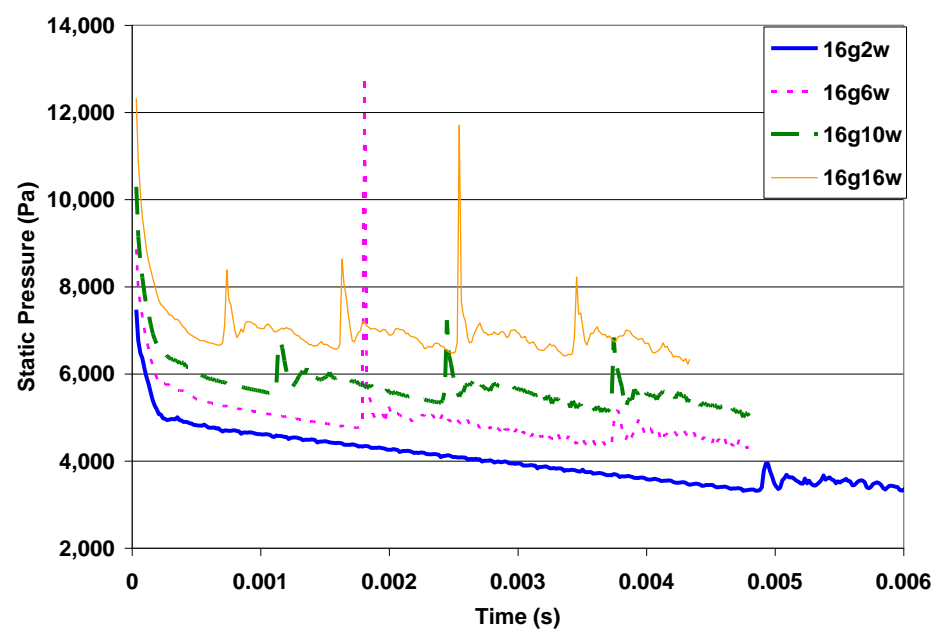

Figure 15: Static pressure fluctuation at air inlet during slug formation at T-junction

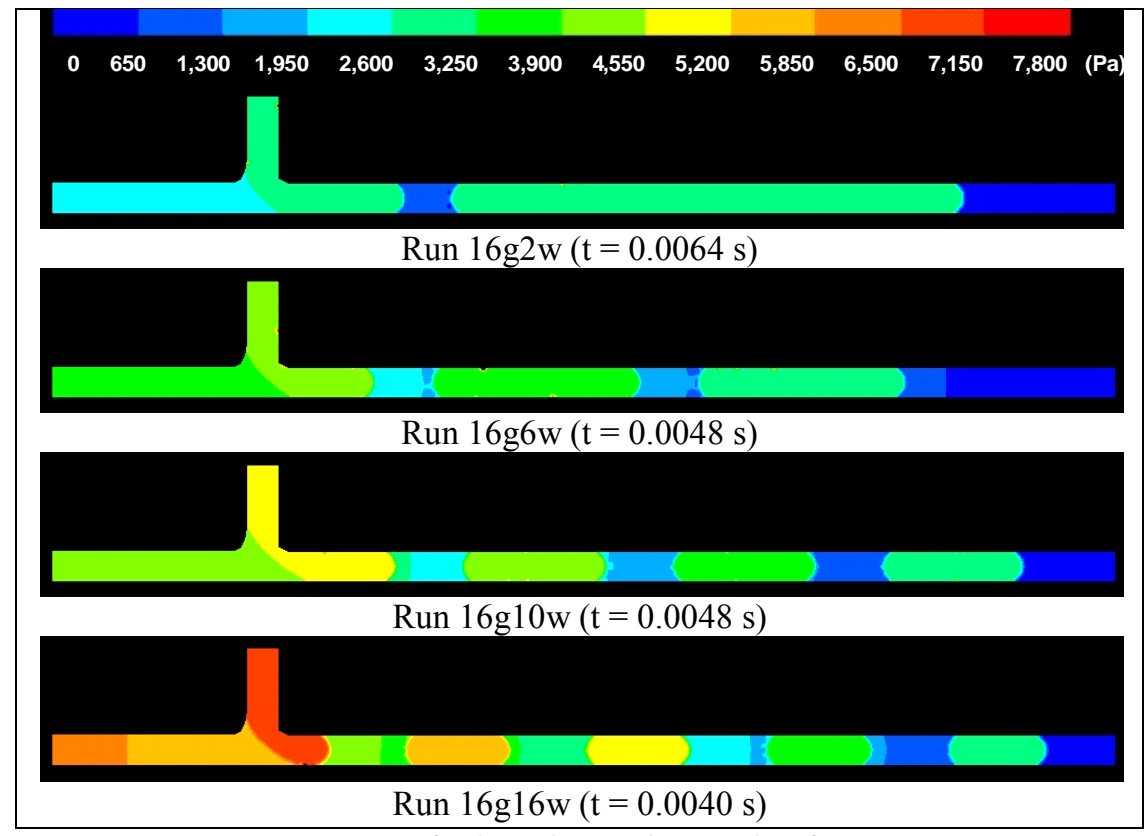

Figure 16: Static pressure of selected runs during slug formation at T-junction

A better understanding of the static pressure trend is obtained by tracking the pressure contour over time, which is done for run $16 \mathrm{~g} 16 \mathrm{w}$ in Figure 17. It can be seen that during necking the static pressure begins to increase. During necking, the gas passes through a smaller area, increasing its velocity and causing the pressure upstream to rise. Once the neck breaks and the gas slug disconnects from the gas inlet channel, the interface shape is severely disrupted and the curvature is excessive. As a result the Laplace pressure increases and static pressure increases further. Once the interface retracts to a spherical cap shape, the Laplace pressure is reduced and the inlet static pressure decreases. 


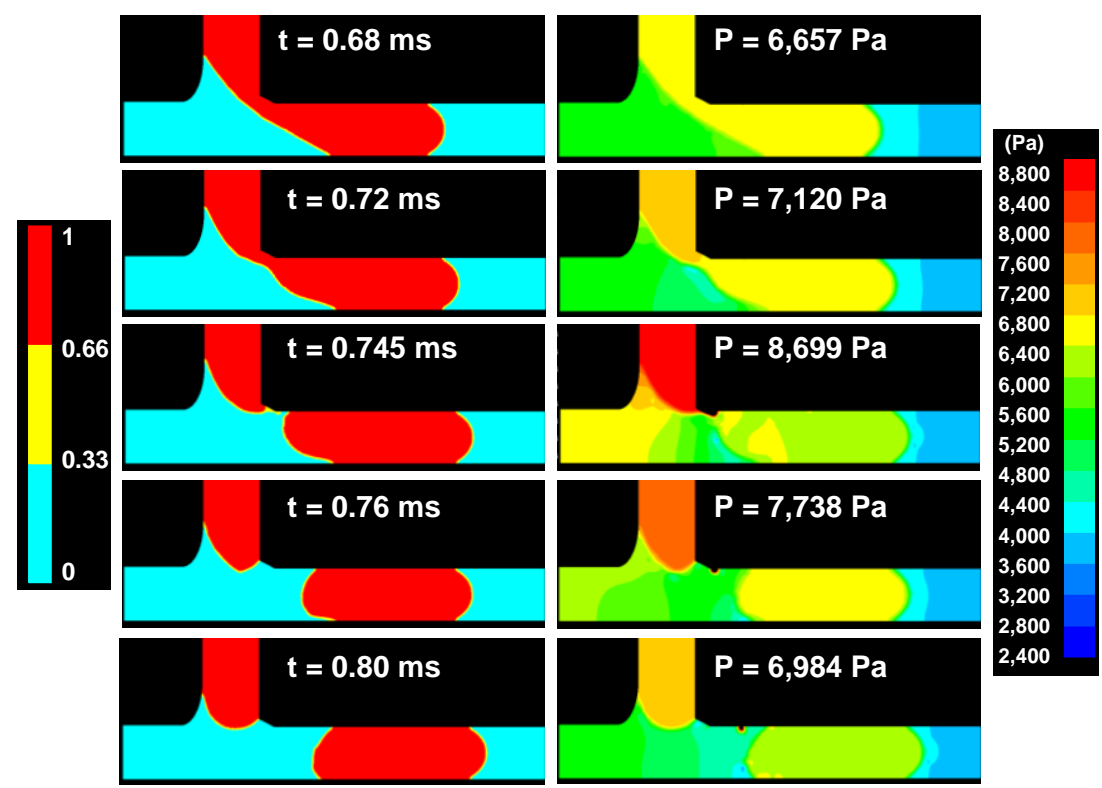

Figure 17: Gas volume fraction (left) and static pressure (right) contours during slug formation at T-junction

\section{Conclusions and future plans}

Numerical modeling of microfluidic two-phase flow is a challenging problem, exacerbated by difficulties in designing experimental systems that can be easily represented in computational simulation. This paper provided detailed information on a microchannel T-junction geometry that can be accurately sketched into a computational mesh. It also provided detailed results of CFD modeling in FLUENT, along with the assumptions used to represent the experimental flow conditions. These modeling results can be useful for comparison of the same problem solved by user-built CFD codes, other versions of commercial CFD codes, or even newer updates of FLUENT software. These reproduced results can then be judged as to whether they are in agreement with FLUENT, which is an advanced and popular CFD code, or even if they predict flow behavior that better matches experimental observations. On the other hand, the experimental methods and results described in detail in this paper can be used by CFD modeling researchers interested in studying in more depth the complexities of the problem, such as better describing the flow conditions by utilizing compressible flow models, dynamic inlet flow boundary conditions, larger computational domains to include the entire microchannel chip, refined wall boundary meshes, dynamic contact angle and contact-line slip models, and so forth. These are complex tasks, but with the continuing advances in the field of computational fluid dynamics and the ever increasing research base solving these problems, a better understanding of the fluid dynamics and physics at the micrometer scale will surely be gained in time.

\section{Acknowledgements}

This work was supported by grants from the Natural Sciences and Engineering Research Council of Canada (NSERC) and the University of Toronto.

\section{References}

[1] Santos R.M., Kawaji M., Numerical modeling and experimental investigation of gas-liquid slug formation in a microchannel T-junction, INT J MULTIPHASE FLOW, 2010, 4, 314-323

[2] Dai L., Cai W., Xin F., Numerical study on bubble formation of a gas-liquid flow in a T-Junction microchannel, CHEM ENG TECHNOL., 2009, 32, 1984-1991

[3] van der Graaf S., Nisisako T., Schroën C.G.P.H., van der Sman R.G.M., Boom R.M., Lattice Boltzmann simulations of droplet formation in a T-Shaped microchannel, LANGMUIR, 2006, 22, 4144-4152 
[4] Gupta A., Kumar R., Effect of geometry on droplet formation in the squeezing regime in a microfluidic Tjunction, MICROFLUID NANOFLUID., 2010, 8, 799-812

[5] Brauner N., Moalem-Maron D., Identification of the range of small diameter conduits, regarding two-phase flow pattern transition, INT. COMMUN. HEAT MASS TRANSFER, 1992, 19, 29-39

[6] Akbar M.K., Plummer D.A., Ghiaasiaan S.M., On gas-liquid two-phase flow regimes in microchannels, INT. J. MULTIPHASE FLOW, 2003, 29, 855-865

[7] Garstecki P., Fuerstman M.J., Stone H.A., Whitesides G.M., Formation of droplets and bubbles in a microfluidic T-junction - scaling and mechanism of break-up, LAB CHIP, 2006, 6, 437-446

[8] Kawahara A., Chung P.M.-Y., Kawaji M., Investigation of two-phase flow pattern, void fraction and pressure drop in a microchannel, INT J MULTIPHASE FLOW, 2002, 28, 1411-1435

[9] Qian D., Lawal A., Numerical study on gas and liquid slugs for Taylor flow in a T-junction microchannel, CHEM ENG SCI., 2006, 61, 7609-7625

[10] Freire S., Wheeler A.R., Proteome-on-a-Chip: Mirage, or on the Horizon?, LAB CHIP , 2006, 6, 1415-1423

[11] Fiddes L., Young E.W.K., Kumacheva E., Wheeler A.R., Flow of Microgel Capsules through Topographically Patterned Microchannels, LAB CHIP, 2007, 7, 863-867

[12] Cabral J.T., Hudson S.D., Microfluidic approach for rapid multicomponent interfacial tensiometry, LAB CHIP, 2006, 6, 427-436

[13] Feng X., Yi Y., Yu X., Pang D-.W., Zhang Z-.L., Generation of water-ionic liquid droplet pairs in soybean oil on microfluidic chip, LAB CHIP, 2009, 10, 313-319

[14] Takei G., Nonogi M., Hibara A., Kitamori T., Kim H-.B., Tuning microchannel wettability and fabrication of multiple-step Laplace valves, LAB CHIP, 2007, 7, 596-602

[15] Fu T., Ma Y., Funfschilling D., Zhu C., Li H.Z., Squeezing-to-dripping transition for bubble formation in a microfluidic T-junction, CHEM ENG SCI., 2010, 65, 3739-3748

[16] Yun J., Lei Q., Zhang S., Shen S., Yao K., Slug flow characteristics of gas-miscible liquids in a rectangular microchannel with cross and T-shaped junctions, CHEM ENG SCI., 2010, 65, 5256-5263

[17] Hwang D.J., Choi T.Y., Grigoropoulos C.P., Liquid-assisted femtosecond laser drilling of straight and threedimensional microchannels in glass, APPL. PHYS. A, 2004, 79, 605-612

[18] Matsuo S., Tabuchi Y., Okada T., Juodkazis S., Misawa H., Femtosecond laser assisted etching of quartz: microstructuring from inside, APPL. PHYS. A, 2006, 84, 99-102

[19] Hoffman R.L., A study of the advancing interface, Part I: interface shape in liquid-gas systems, J. COLLOID INTERFACE SCI., 1975, 50, 228-241

[20] Fluent, FLUENT 6.2 documentation, Fluent Incorporated, Lebanon, New Hampshire, USA, 2006

[21] Kawahara A., Sadatomi M., Kumagae K., Effect of gas-liquid inlet/mixing conditions on two-phase flow in microchannels, PROGR MULTIPHASE FLOW RES., 2006, 1, 197-204, (in Japanese)

[22] Lockhart R.W., Martinelli R.C., Proposed correlation of data for isothermal two-phase, two-component flow in pipes, CHEM ENG PROG., 1949, 45, 39-48

[23] Chisholm D., A theoretical basis for the Lockhart-Martinelli correlation for two-phase flow, INT J HEAT MASS TRANSFER, 1967, 10, 1767-1778

\section{Appendix}

User Defined Function for tracking numerical slugs in FLUENT (C language)

\#include "udf.h"

DEFINE_ON_DEMAND(track_bubble)

\{

/* define variables */

int phase_domain_index;

real

vel_sum[ND_ND],co_ord1[ND_ND],co_ord[ND_ND],volume,mili,nano,nanosym,xmin,xmax,size, average_vel ocity[ND_ND],x[ND_ND];

cell t cell;

Thread*cell_thread;

Domain *subdomain, *mix_domain=Get_Domain $(1)$;

NV_S(vel_sum, $=, 0$.$) ;$

NV_S(co_ord,=,0.);

volume $=0$;

mili $=0$.;

nano $=0$.; 
$\mathrm{xmin}=0.003885$;

$\mathrm{xmax}=0$;

$\mathrm{Ls}=0$;

NV_S(average_velocity, $=, 0$.$) ;$

NV_S(co_ord1,=,0.);

/* loop over all subdomains (phases) in the superdomain (mixture) */

sub_domain_loop(subdomain,mix_domain, phase_domain_index)

\{

/* loop if secondary phase see phases panel in FLUENT to get ID for mixture $=1$ and phases */

if (DOMAIN_ID(subdomain) $==2$ )

\{

/* loop over all cell threads in the secondary phase domain */

thread_loop_c (cell_thread,subdomain)

\{

/* loop over all cells in secondary phase cell threads */

begin_c_loop(cell,cell_thread)

\{

C_CENTROID(x,cell,cell thread);

$/ *$ define beginning and end coordinates, $\mathrm{x}$-values, of scan region, to ensure only slug on interest is captured*/ if $(x[0]>0.002076)$

\{

if $(x[0]<0.003885)$

\{

$/ *$ extract and store relevant flow data*/

co_ord $[0]+=\left(\right.$ C_VOF $($ cell,cell_thread $) * C_{-}$_VOLUME $($cell,cell_thread $) * x[0]$;

co ord $[1]+=(\mathrm{C}$ VOF(cell,cell thread $) * \mathrm{C}$ VOLUME(cell,cell thread $) * x[1]$;

co_ord $[2]+=\left(C_{-}^{-}\right.$VOF $($cell,cell_thread $) * \mathrm{C}^{-}$VOLUME(cell,cell_thread $) * x[2]$;

vel_sum $[0]+=\left(\bar{C} \_\operatorname{VOF}(\right.$ cell,cell_thread $) * \bar{C}$ _VOLUME(cell,cell_thread $) * C$ CU(cell,cell_thread $)$;

vel $\operatorname{sum}[1]+=(\mathrm{C}$ VOF (cell,cell thread $) * \mathrm{C}$ VOLUME(cell,cell thread $) * \mathrm{C}$ V(cell,cell thread);

vel_sum[2] $+=\left(\mathrm{C}_{-}^{-} \mathrm{VOF}(\text { cell,cell_thread })\right)^{*} \mathrm{C}_{-}^{-} \mathrm{VOLUME}\left(\mathrm{cell}, \mathrm{cell}{ }_{-}\right.$thread $) * \mathrm{C}_{-}^{-} \mathrm{W}($ cell,cell_thread $)$;

volume $+=(\mathrm{C}$ VOFF(cell,cell_thread $))^{*} \mathrm{C}$ VOLUUME(cell,cell_thread); /*sum of cell volumes*/

mili $=($ C_VOF $($ cell,cell_thread $)) * C_{-}$VOL̄UME(cell,cell_thread $) * 1000000 ; / *$ cell volume in mililiters*/

nano $+=\overline{\text { mili }} * 1000000 ;{ }^{*}$ sum of cell volumes in nanoliters $* /$

if $($ C_VOF $($ cell,cell_thread $)>0.5)$

\{

if $(x[0]<x \min )$

\{

$\mathrm{xmin}=\mathrm{x}[0]$

\}$/ *$ close min if $* /$

if $(x[0]>x \max )$

\{

$\mathrm{xmax}=\mathrm{x}[0]$;

\}$/ *$ close max if*/

\} $/ *$ close max min vof if $* /$

\} $/ *$ close position end if loop */

\} / close position start if loop */

\}

end_c_loop(cell,cell_thread)

\} $/ *$ close secondary phase domain $* /$

\} / close domain ID loop */

\} / close subdomain loop */

/*calculate relevant parameters*/

NV_VS(co_ord1,=,co_ord,/,volume); /*slug centroid position: $\mathrm{x}, \mathrm{y}, \mathrm{z} * /$

NV_VS(average_velocity,=,vel_sum,/,volume); /*slug velocity, vs, in meters per second; $\mathrm{x}, \mathrm{y}$ and $\mathrm{z}$ directions*/

$\mathrm{Ls}=1000000 *(\mathrm{xmax}-\mathrm{xmin}) ; / *$ slug length, Ls, in micrometers*/

nanosym $=$ nano $* 2 ; / *$ slug volume, Vs, in nanoliters $* /$

/*print values on screen*/ 
printf("Centroid[0] $=\%$ fnCentroid[1]=\%flnCentroid[2]=\%fln",co_ord1[0],co_ord1[1], co_ord1[2]);

printf("V_Centroid[0]=\%flnV_Centroid[1]=\%flnV_Centroid[2]=\% $\mathrm{f} \backslash \mathrm{n}$ ",average_velocity[0],average_velocity[1], average_velocity[2]);

printf("Slug Volume=\%fln",nanosym);

printf("Xmin=\%fln",xmin);

printf("Xmax=\%fln",xmax);

printf("Slug Length=\% $\%$ fn",Ls);

\} * close define on demand */ 